\title{
La política y lo político: una aproximación conceptual
}

En este capítulo se revisan algunos postulados teóricos que son pertinentes para esclarecer el concepto de lo político. Inicialmente se presenta la concepción de los clásicos Aristóteles y Platón; luego se profundiza en la concepción de la política como el control del poder garantizado por el Estado a partir de Hobbes, Maquiavelo y Rousseau; en contraposición se ahonda en una concepción de la política más allá de la relación con el Estado a partir de la reflexión de Arendt. Seguidamente se revisa el concepto de lo político con Smith, quien fue el primer teórico que se ocupó de definirlo a partir de la noción de amigo-enemigo. Posteriormente, con Laclau y Castoriadis se profundiza en las relaciones conceptuales de esta noción y su pertinencia en nuestro tiempo, para finalmente establecer el vínculo entre lo político y la estética (Rancière) como una posibilidad de apertura y transformación de la dinámica social contemporánea.

\section{La política y los clásicos}

Para Aristóteles el punto central de la política se ubica en la polis ( $p o-$ litai), como comunidad de ciudadanos, vinculado al concepto de ciu$d a d$, a partir de características geográficas (comunidad de hombres que 
habita un lugar determinado), pero también simbólicas, pues implica una estructura institucional que determina esa comunidad.

La importancia de la polis como punto nodal para el pensamiento aristotélico radica en que solo en el entre nos o el estar con otros (postulado que retoma Arendt) surge la política como medio y fin para la convivencia y el aseguramiento de la vida en un sentido amplio.

Para Aristóteles la palabra Politikon era un adjetivo para la organización de la polis y no una caracterización arbitraria de la convivencia humana, no se refería de ninguna manera a que todos los hombres fueran políticos o a que en cualquier parte donde viviesen hombres hubiera políticas, o sea, polis. De su definición quedaban excluidos no solamente los esclavos sino también los bárbaros [...] a lo que se refería es a que es una particularidad del hombre que puede vivir en una polis y que la organización de ésta representa la suprema forma humana de convivencia y es, por lo tanto, humana en un sentido específico, igualmente alejado de lo divino, que puede mantenerse por sí solo en plena libertad y autonomía, y de lo animal, en que la convivencia -si se da- es una forma de vida marcada por la necesidad. La política, por lo tanto, en el sentido de Aristóteles, no es en absoluto una obviedad ni se encuentra dondequiera que los hombres convivan. Según los griegos, sólo la hubo en Grecia e incluso allí por un espacio de tiempo relativamente corto. (Arendt, 1993, pp. 68 y 69)

Esta condición del vivir con otros es una situación natural de la polis. Para Aristóteles lo político se fundamenta en el deseo de vivir bien, y para lograr este fin es necesario juntarse espontáneamente a una comunidad, cuya autarquía (capacidad de bastarse a sí misma) hace posible una vida valiosa para los individuos. Esta apuesta del vivir bien implica una dimensión política por cuanto "vivir, zên, sólo se completa como eu $z e ̂ n$, 'vivir bien', fórmula que equivale a la buena vida política, la cual frente al mero vivir biológico, zên, da la plena dimensión de la vida humana" (Poratti, 1999, p. 24). Así es como se entiende la célebre afirmación de Aristóteles de que el hombre es animal de polis, animal cívico (político); gracias a que tiene lenguaje (logos), además de voz (phoné). 
El logos equivale a la "palabra”, lo que supone para Aristóteles expresión, definición, proposición, proverbio, mandato, argumentación, pensamiento. "El logos existe para significar lo justo y lo injusto" (Fernández, 2000, p. 25). Esta vinculación del logos como condición existencial de la polis implica una tradición demarcada por los sofistas y retomada por Platón, que evoca al agorá, como escenario de discusión y argumentación privilegiado.

El agorá, palabra que no significa originariamente un lugar, sino la institución que en Homero era la discusión solemne de los jefes en presencia del ejército, en la cual el que hablaba estaba religiosamente protegido por la sustentación del cetro: transposición regulada, pues, del conflicto a la palabra. Este juego, llevado a cabo ahora por las clases, partes y partidos que se enfrentan en la ciudad, respaldado y regulado por la ley escrita e impersonal, será el que ocupe el lugar vacío del cetro. Y con ello tenemos la Ciudad. El conflicto llevado a la palabra sobre el fondo de la ley será la condición de posibilidad del logos. Unos siglos después Aristóteles conectará esencialmente el zôon politikón, el ser vivo a cuya naturaleza corresponde vivir en polis, con el zôon lógon ékhon, aquél a cuya naturaleza corresponde el logos, como la misma definición. (Poratti, 1999, p. 18)

Así, la polis se convierte en el ámbito privilegiado donde se produce lo político, a través del ágora, como espacio público que permite la discusión y el desarrollo de la vida política como actividad fundante de la sociedad y el logos como esencia de la práctica política. Esta condición la veremos más adelante y será criticada por Rancière.

El logos se torna en el instrumento político por excelencia, la clave de la autoridad en el Estado, la forma de comando y de persuasión. La palabra se transforma en el elemento central de la práctica política, una práctica que supone el disenso, la diferencia, el conflicto, pero cuyo medio primordial es el uso de la palabra. La palabra supone por otro lado, un elemento central para pensar el espacio público, la existencia misma de un público, de un juez 
que decida en última instancia entre los distintos argumentos [...]. De esta forma la política adviene también seducción. (Rossy y Amadeo, 2002, p. 63)

En Atenas el juego político interno era determinado por el lenguaje y la argumentación persuasiva, como posibilidad de encontrar la verdad, pues en el fondo toda realidad tiene una estructura inteligible que hay que desentrañar a través del logos, es decir, de las enunciaciones de los hombres, y así ponerlas a prueba por medio de unas formas objetivas de verificación.

En esta perspectiva, el logos se establece como término que funda la condición política de los ciudadanos pertenecientes a la polis, pero también como horizonte de sentido (vinculado al saber) en el que se enmarca la política; además, plantea esa escisión entre los que pueden o no dirimir los destinos de la polis, es decir, establece las fronteras entre aquellos que están facultados (por condición natural o por su educación) con el logos y no solo con phoné.

El modelo político platónico, expresado en la República, se encuentra íntimamente vinculado a su teoría del conocimiento. El conocimiento genuino, si se precia de tal, tendrá que derivarse del ámbito estable de las formas inmateriales. El mundo de lo sensible, en radical contraposición a aquél, será el mundo del cambio, del puro movimiento, del cual no podrá existir el puro conocimiento. Vale decir que para Platón, una epistemología de lo sensible es por su propia estructuración lógica un auténtico absurdo y contradicción. Las categorías del mundo de la percepción sensorial eran las categorías descriptivas y evaluativas del mundo existencial de la actividad política (terreno de la doxa) mientras que las categorías que describen a las formas indican lo que podía llegar a ser el mundo de la política, siempre y cuando el mismo estuviera guiado por la filosofía. (Rossy y Amadeo, 2002, p. 65)

Por lo tanto, se produce la areté, que para Platón tenía que ver con la virtud y las condiciones socialmente valoradas que debían tener aquellos que dirigen los destinos de la polis, y que se encontraba en ciertos 
hombres como condición natural, o se podía adquirir ligándola al saber y a la educación sofística.

La areté, además de otorgar legitimidad en el ejercicio del poder, se convierte para Platón en la base para establecer el principio de justicia y ética vinculado a la política, y que posteriormente Aristóteles destaca como condición principal del ejercicio político y del buen vivir.

Aristóteles, por su parte, enuncia que "la virtud de la justicia es cívica (política), porque la justicia es el orden de la comunidad cívica (política), y la justicia es discernimiento de lo justo" (Fernández, 2000, p. 29). Dicha justicia se establece entre los hombres a partir de la tendencia a unirse, a experimentar, discernir y poner orden en común en medio de la contingencia que esto implica. De esta lógica se desprende la idea de que el ciudadano para Aristóteles es aquel que participa en una democracia, como derecho reconocido constitucionalmente en el poder deliberativo y judicial, a través del logos. Así, surge la premisa de que el ciudadano contribuye a hacer las leyes que rigen el Estado, en el sentido de un régimen directo.

Aristóteles entiende que la mejor constitución debe responder al principio de atender del mejor modo posible a la ventaja común (koiné sympheron) (Fernández, 2000, p. 29), y la responsabilidad de constituir ese poder político se le otorga a quienes participen en mayor medida de la excelencia política, que no puede ser atribuida ni a la riqueza, ni al nacimiento, ni a la libertad, sino a aquellos que cumplen con la aretaí y tienen como principio asegurar las ventajas comunes de vivir en la polis, como construcción humana.

Esta apuesta devela al conflicto como un punto que distancia la reflexión política de Platón y Aristóteles, por cuanto el primero produce, por una parte, la exclusión del conflicto para garantizar el orden establecido a través de la dinámica estatal y el segundo postula su tratamiento como posibilidad de maduración y de construcción de una vida común, negociada.

El objeto de la política para Platón se enmarca en una teoría del orden que excluye o por lo menos considera como una "patología" al conflicto social. Para Aristóteles, el conflicto es constitutivo de las relaciones humanas y por tanto de la política; vale decir, ésta 
es la razón por la que su preocupación primaria no es la temática del orden sino la problemática de la gobernabilidad, donde el conflicto aparece como un a priori que no se bebe anular sino mediatizar o administrar. (Rossy y Amadeo, 2002, p. 71)

Para Platón el ámbito político tenía una tendencia natural al desorden y por eso el orden como armonía debía ser impuesto desde el exterior de la práctica política a través de las leyes; así, la conflictividad se establece con los bárbaros, pero en el interior de la polis o de la república. Dado que la ciudad se establece solo a partir de la necesidad de que cada individuo ocupe el lugar que naturalmente le corresponde, y en la medida en que esto ocurre, se produce el orden, aunque no necesariamente un orden político. "La existencia del orden político es la existencia de mediaciones que permitan el encaminamiento del conflicto, sin que éste implique la destrucción de la unidad política, mecanismos que atenúen las fuerzas vitales de la vida asociada, permitiendo su existencia, intentando reencauzarlas o transformándolas creativamente cuando ello sea posible" (Rossy y Amadeo, 2002, p. 69).

Platón unía política, ética y metafísica supeditándolas a la posibilidad de la contemplación de la idea del bien a través del logos (idea que comparte también Aristóteles), pero no advierte el conflicto primero que implica esta idea, en cuanto el logos tiene originalmente las huellas del conflicto.

Con Heráclito aparece por primera vez en el lenguaje del pensamiento la palabra logos, que significa tanto la inteligibilidad que hay en la realidad como la posibilidad humana de captarla y de decirla. Ahora bien, el logos heraclíteo, en tanto estructura o ley del acontecer, responde a la dinámica de los opuestos, el conflicto que anida en la justicia misma y la constituye. "Hay que saber que la guerra es común y la justicia discordia y todo sucede según la discordia y necesariamente" [...] según este fragmento, la inteligencia y el lenguaje del hombre están respaldados por "lo común" de todas las cosas (esto es, el logos), así como la ley, que es lo común político, respalda a la ciudad. Más aún, "todas las leyes humanas se alimentan de uno, lo divino" (o "de una ley, la divina"): 
es decir, la ley política misma, equilibrio de un conflicto, es como un arroyo que procede directamente de esa esencia conflictiva y a la vez ocultamente armoniosa que rige todo. La armonía es el ritmo del conflicto, que es raigal e inextirpable. (Poratti, 1999, p. 18)

De esta idea se desprende la dificultad de construir un marco común entre hombres dotados de libertad y autonomía, que ubique a la justicia como máxima de vida en comunidad, desconociendo que esa justicia se configura solo entre tensiones éticas y políticas que surgen en el entre nos, es decir, del conflicto como ámbito eminentemente político.

Aristóteles, por su parte, identifica la relación entre política y ética desde una racionalidad y moralidad prácticas que residen en los ciudadanos, no solo en los dirigentes; distinguiendo entre virtudes dianoéticas y éticas, entendiendo las primeras como las facultades racionales puras y las segundas como las facultades racionales, pero legislando en el terreno del deseo (Rossy y Amadeo, 2002, p. 71).

Así, la virtud suprema de la justicia determina la existencia de la polis, "a partir de una moralidad media, reivindicando a la politeia como el mejor régimen posible del gobierno, pues es en este régimen donde convergen una eticidad práctica formulada por la teoría del término medio y vinculada consecuentemente a la moderación y estabilidad del estamento medio" (Rossy y Amadeo, 2002, p. 72). Aristóteles aparece del todo ajeno a la idea de que las comunidades políticas solo pueden nacer de una especie de contrato destinado a superar las tendencias hostiles, acuñando la idea de constitución de comunidades políticas desde la construcción colectiva que transita entre la necesidad y la contingencia.

Hasta este punto, se pueden encontrar diferencias significativas entre Platón y Aristóteles en la concepción de la política, por cuanto se devela una perspectiva más vertical que garantiza el orden y la vida en sociedad, y otra que incluye más aristas que complejizan la condición humana y la posibilidad de construir en común. Así, se puede ubicar una diferencia más o menos evidente entre la política y lo político, en cuanto la primera se vincula a una condición estructurante de la sociedad que determina unas leyes y unas prácticas políticas reguladas por el logos, la ética y la justicia, como posibilidad de existencia de 
una colectividad, y a lo político como una condición aún ignorada que tiene que ver con la práctica política, pero que se circunscribe al ágor y al logos, junto a otras condiciones particulares que residen solo en los ciudadanos. No obstante, se advierte al conflicto como una tensión permanente en ese entre nos, que cumple con la función de dinamizar esas relaciones y que, hasta este punto, se subsume a la práctica política.

\section{La política y los contractualistas}

La justicia se concibe posteriormente en un punto central de reflexión y de organización social, que posibilita la generación de mecanismos que garanticen el orden político. Por eso, surge la preocupación por lo que tiene que ver con la teoría del Estado y con el arte o ciencia de gobernar. De ahí que se pueda analizar a pensadores como Maquiavelo, Hobbes y Rousseau, quienes se ocuparon de profundizar en la acción política en relación con la institución de un Estado que garantice las bases de la sociedad y de la vida política de una nación.

En esta parte se presenta inicialmente cuál es la noción de hombre que llevó a estos autores a construir su andamiaje teórico, para posteriormente comprender cómo entienden la idea de justicia, libertad e igualdad a partir de la cual establecen una acción política específica en relación con la idea contractual del Estado como garante del ejercicio político.

Para Nicolás Maquiavelo (1496-1527) el hombre es un ser egoísta y ambicioso por naturaleza, que busca favorecer su propia existencia y bienestar por encima de todo; además, posee deseos infinitos e insaciables, que chocan inevitablemente con las apetencias similares de los demás, lo cual produce inevitablemente la violencia que ha marcado la historia humana en su vida privada y, con mayor razón, en la esfera pública. "La fuerza inmutable de las pasiones y la "tristizia" innata de los hombres parecerían condenar al fracaso los intentos de detener o controlar la violencia por medio de las costumbres y las leyes" (Papacchini, 2000, p. 97).

El hombre no es apto por naturaleza para la política ni para la vida social. Al hombre hay que doblegarlo, hay que someter su 
carácter natural para conseguir su disposición para la vida política. La función del Estado radica en hacer que el hombre no actúe según sus disposiciones naturales, sino según criterios que hagan posible la vida en común. (Cortés, 2003, p. 98)

Por su parte, Thomas Hobbes (1588-1679) asume también la idea de que la naturaleza de lo humano se fundamenta en un principio de egoísmo racional que busca la supervivencia. Así, los hombres, guiados por el interés propio, son ególatras, pues buscan reconocimiento, es decir, honor y gloria en beneficio propio.

Igual que los griegos, Hobbes comprende a la razón como logos, y advierte que el desarrollo de todas las potestades de la razón se funda en la capacidad para el lenguaje (Carrillo, 2003, p.130). Así, el ser humano por la razón y el lenguaje es capaz de satisfacer sus deseos; no obstante, busca asegurar en el presente sus necesidades posteriores, por eso se asegura de generar una estabilidad a futuro. Es decir, toda acción humana tiene origen en el deseo; sin embargo, gracias a la razón y al lenguaje — propiedades que potencian la experiencia sensible en su capacidad de cálculo y previsión- se genera una transformación en el objeto de deseo (garantizar su supervivencia), que no se limita a los objetos directos de la experiencia, sino al poder como objeto, es decir, a prever y tener a su favor los medios para adquirir satisfacciones futuras.

Así pues, se produce otra transformación en el interior de las dinámicas de las relaciones: el deseo de poder se convierte en deseo de dominio sobre los demás; este dominio no sólo es uno de los poderes instrumentales, sino que es, a su vez, el objeto hacia el que se movilizan todos los demás poderes. O sea, el principal recurso de poder para un individuo son los demás individuos, y por ello, cada cual busca poner al servicio de sí los poderes o capacidades de los demás. (Romero, 2002, p. 133)

Entonces, el conflicto social es inevitable al tener cada cual un objeto diferente de deseo. Esto es lo que Hobbes denomina como el estado de naturaleza propio del vivir en comunidad, es decir, un estado de 
guerra de todos contra todos a partir de ese deseo de poder que habita en cada sujeto. La inclinación natural humana primordial es un "perpetuo e incansable deseo de conseguir poder tras poder, que sólo cesa con la muerte" (Romero, 2002, p. 122).

Esta "guerra de todos contra todos" se entiende como voluntad de confrontación violenta de carácter permanente, como signo de esa tensión irresoluta que produce la inclinación a la lucha y al conflicto sin garantía de solución entre los sujetos racionales, que buscan ante todo la satisfacción de sus intereses individuales y la influencia sobre la voluntad de los otros.

En ese estado de la naturaleza, surge a la vez un principio de igualdad; en tanto, en la esperanza de conseguir los propios fines, todos los hombres están dotados de unas condiciones que los facultan naturalmente para este fin. Por ende, no es la constitución interna de los individuos la razón en pugna, sino la dinámica de las relaciones sociales que en la convivencia fomentan ese afán de lucha. Para Hobbes surgen tres razones que fomentan la pugna entre los humanos: la rivalidad o deseo de superioridad, la desconfianza mutua y el afán de honor, riqueza y autoridad (Carrillo, 2003, p. 138). A partir de estas características humanas se genera un temor recíproco de todos contra todos, que solo se neutraliza con la existencia de leyes naturales que apelen a la racionalidad y al temor a la muerte para generar mecanismos de paz y garantía de condiciones básicas de supervivencia en comunidad. "El derecho natural es esa potestad de hacer todo lo que está al alcance para conservar la vida propia; la ley natural significa lo contrario de la libertad de hacer, puesto que es una norma que le pone límites al derecho natural, su objeto es la conservación de la vida" (Romero, 2002, p. 123).

Para Jean Jacques Rousseau (1712-1778), el hombre —incluso en su estado de naturaleza- es un ser sin maldad, en el que predominan el instinto de autoprotección (amor de sí) y la piedad (repugnancia por el sufrimiento ajeno), pero a medida que va creciendo la población se van juntando grupos; esa unión crea necesidades y para cubrirlas el hombre inventa mecanismos que garanticen su satisfacción, pero el deseo de acumulación es más fuerte, por lo tanto, es la propiedad privada el fruto de la discordia que genera en los hombres la envidia, el sometimiento y la desigualdad. 
Para este autor, el origen de la desigualdad se produce en la asociación humana. En el hombre se encuentran dos clases de desigualdad: una natural o física (diferencias del cuerpo y de las cualidades del espíritu) y otra de orden moral o política, que depende de una convención social y está autorizada por el consentimiento de los hombres, es decir, por los privilegios que existen para algunos en perjuicio de otros (Urquijo, 2002).

Este tipo de desigualdad se legitima socialmente mediante el establecimiento de la propiedad y las leyes. Así, la desigualdad moral, autorizada por el derecho positivo, es contraria al derecho natural. Uno de los intereses de Rousseau es establecer clases de desigualdades, pero entiende que son las cualidades personales el origen de ellas y, en últimas, se reducen a la acumulación de riqueza, pues es la más útil para alcanzar el bienestar social y para adquirir todas las demás (Urquijo, 2002, p. 172).

En cuanto a la concepción de libertad, justicia e igualdad en estos autores, Maquiavelo entiende que el orden estatal cumple la función ética de preservar la vida y libertad, en la medida en que la virtud del ciudadano y su apego a las instituciones es una condición indispensable para la fortaleza y libertad del Estado (Papacchini, 2000, p. 108). No obstante, entiende que la violencia es justificable para restablecer el orden social, ante la ineficacia de cualquier otra clase de herramientas.

Lo que Maquiavelo busca entonces es fundamentar que la acción del Estado no se debe limitar desde la moral. Así, el problema fundamental de la política es establecer un orden que garantice la seguridad de todos aquellos que hacen parte de una comunidad política.

Para Maquiavelo, los límites de la acción del Estado se definen en función de las posibilidades del Estado mismo para alcanzar sus propósitos políticos más fundamentales, y en ningún sentido acepta que los límites de la acción política sean trazados desde una esfera externa a ella. El límite de la acción estatal lo traza el gobernante que sea capaz de conservar la unidad del poder soberano en el Estado, si mantiene el Estado es un buen gobernante, si no lo hace es un fracaso. (Cortés, 2003, p. 101) 
Por eso, Maquiavelo profundiza en el principio de autonomía del quehacer político desde el ejercicio del soberano, el cual se entiende a partir de las acciones políticas que son necesarias para mantener un Estado, en el cual el uso de la violencia se justifica como medio considerado solamente en su relación con los fines que persigue.

Una primera consecuencia de esta tesis es la diferenciación de los ámbitos de acción y de las respectivas condiciones de validez: al ámbito de la moral le corresponde como condición de validez el mundo del valor y al de la política le corresponde la eficiencia pragmática que se mide en la relación medios-fines. La segunda consecuencia de esta tesis es la afirmación de que los valores políticos poseen un más alto valor que los de la moral. (Cortés, 2003, p. 113)

Con esto Maquiavelo logra separar y diferenciar el ámbito de la ética del campo de la política, es decir, apartar los asuntos de la moral privada de los asuntos concernientes a la organización pública. Por eso afirma que cuando el soberano elige comprometerse con las tareas políticas implicadas en la construcción de un Estado, las acciones no son ni buenas ni malas (Cortés, 2003).

Por su parte, Hobbes asume que la única forma que puede regular la convivencia entre los seres humanos es a través de un orden artificial. Un orden en el cual la idea de libertad es compatible con la de poder absoluto del soberano y, por lo tanto, de total obediencia del súbdito como cuestión política, pues no hay contradicción entre obedecer a Dios y obedecer al soberano (Romero, 2002). Sin embargo, establece que el poder soberano se produce por consentimiento de los asociados, es decir, como poder civil y no solo eclesiástico.

Hobbes define el derecho natural como "la libertad que cada humano tiene de usar su propio poder para preservar su propia vida $y$, por tanto, de hacer cualquier cosa que según su buen juicio y razón conciba como el mejor medio para conseguirlo". De este modo, "una ley natural es un precepto o regla general encontrada por la propia razón humana, por la cual se le prohíbe al ser humano hacer cualquier cosa destructiva para su vida o que le arrebate 
los medios para preservarla o que omita aquello con lo cual puede preservarla mejor”. (Carrillo, 2003, p. 143)

De ahí que Hobbes establezca tres principios o leyes fundamentales del derecho natural. La primera tiene que ver con el empeño en lograr el establecimiento de la paz y poner fin a la violencia. Para esto se vale de la segunda ley, que se refiere al firme compromiso de cada cual de satisfacerse con tanta libertad como puedan tener todos los otros, es decir, de esta se deriva la posibilidad de crear pactos que establezcan propósitos comunes. La tercera se refiere a la necesidad de hallar el instrumento capaz de garantizar que todos cumplan efectivamente lo acordado, es decir, apelar al sentido de justicia.

Sin un contrato social, es decir, sin la instauración de un poder civil suficiente para regular a través de las leyes la administración de justicia que debe conformarse a los derechos humanos fundamentales, no puede haber justicia. En este sentido la justicia es el instrumento del poder civil para hacer que todos cumplan con las condiciones de una convivencia pacífica. (Carrillo, 2003, p. 144)

El nuevo orden social es un contrato por el cual los individuos renuncian a ser naturalmente libres. Al aceptar ese orden artificial que establece como necesario la ley natural, hay una renuncia al derecho natural que marcaba la tradición cristiana. Para Hobbes, el derecho natural es equivalente a la libertad total que cada hombre tiene de usar su poder, propio del estado de naturaleza; hecho que lleva finalmente a la guerra. Así, el poder del soberano debe ser absoluto para evitar que los integrantes de la comunidad se enfrenten, para que no renuncien a su libertad natural y se vuelva a la confrontación permanente de la condición humana.

Rousseau introduce el lenguaje jurídico propio de las relaciones privadas entre los hombres para comprender el vínculo entre el soberano y los súbditos, y entiende que este no radica en la sumisión o en la violencia, sino que se instituye voluntariamente por parte de los hombres, quienes renuncian a un estado natural para someterse a las reglas de la sociedad, a través de un contrato social, y así garantizar su seguridad y supervivencia. 
Con lo anterior, Rousseau asume que es solo desde la lógica del contrato social, como modelo político, que los hombres pueden vivir libres e iguales, guiados por un principio de justicia social. "La igualdad es un valor que se funda en la relación entre los hombres, y que se constituye como principio regulador para una sociedad justa y decente" (Urquijo, 2002, p. 157). De ahí que constituyera a la soberanía de la voluntad popular como un fundamento legítimo de la sociedad y el Estado.

El problema central para Rousseau es ¿cuál es el origen de la desigualdad entre los hombres y si está autorizada por la ley natural? Su respuesta es contundente, la desigualdad no está autorizada por la ley natural. El origen de la desigualdad es convencional, pues se da en y por la convivencia que los hombres establecen en su asociación. (Urquijo, 2002, p. 170)

Por eso la importancia de establecer mediante un contrato legal el valor de la igualdad como forma de convivencia social. "De ahí la necesidad de hablar en el ámbito moral o político de una 'igualdad en $\mathrm{X}$ o Y' para distinguir el tipo de igualdad de la que se habla, o sea, una igualdad en derechos, en oportunidades, libertades, ingresos, renta, en el trato social y político, etc.” (Urquijo, 2002, p.172). Este contrato se produce con el ánimo de lograr la paz y garantizar la posesión de cada hombre en particular, en igualdad de derechos.

Con todo lo anterior, se puede establecer que en estos tres autores la acción política de los hombres está supeditada a la regulación de un Estado que establece las normas y las formas de convivencia humana. Sin embargo, en este punto se pueden encontrar diferencias significativas que develan la transición del concepto de Estado y su función social, alcances y dificultades en la definición de la política contemporánea.

Maquiavelo es el primer teórico que conceptualizó al Estado, en la medida en que determinó, en contra del pensamiento político de la antigüedad y de la Edad Media, que el Estado no es la instancia para la autorrealización o para la dirección teológica o moral, sino que es un instrumento de coacción contra las inclinaciones destructivas del hombre (Cortés, 2003, p. 91). 
Asimismo, Maquiavelo establece que los “fundamentos" del Estado son esencialmente dos: las buenas leyes y las buenas armas. Por ende, el príncipe tiene que asumir como imperativo la conservación del Estado, subordinando todo lo demás —incluyendo eventuales consideraciones de carácter moral - al logro de este objetivo prioritario (Papacchini, 2000, p. 87). Con lo anterior, se entiende que el poder estatal no puede sostenerse sin un eficiente aparato de fuerza que lo respalde.

Uno de los aspectos más significativos de la concepción de Maquiavelo es que el Estado es completamente independiente, pero al mismo tiempo está aislado. "Al separar la moral de la política, el Estado queda libre de todo tipo de valoración ética" (Cortés, 2003, p. 90), lo que le permite el uso de la violencia y otros mecanismos necesarios para mantener el orden social.

En sintonía con lo anterior, para Hobbes la cuestión central es la legitimidad del poder soberano encarnado en el Leviatán, como imperativo necesario para crear un orden artificial que garantice la convivencia y la paz entre los hombres, y no solo para vivir, sino también para vivir bien. El poder del Leviatán es extraordinario como el de Dios, pero es producto humano, y por lo tanto es mortal; además, a pesar de ser temible, es necesario para poder convivir, pues su origen tiene como punto de partida el reconocimiento que todos los seres humanos deben hacer de esta necesidad (Romero, 2002, p. 121). Por lo tanto, los humanos tienen que renunciar al derecho natural que poseen y aceptar la fuerza vinculante y recíproca que garantiza la obligatoriedad del pacto colectivo.

Ese poder soberano es sólo político, es decir, sólo poder exterior que no tiene potestad alguna sobre la libertad de pensamiento, de religión, de usos de cada individuo, siempre y cuando tales pensamientos y usos no atenten contra el concepto de bien común, que se sobreentiende ha sido forjado sobre la recta razón. Prevalecen entonces las libertades individuales, que Hobbes llama los silencios de la ley, es decir, lo que las leyes civiles no pueden ni deben reglamentar respecto a la vida privada de los ciudadanos. (Carrillo, 2003, p. 146) 
Así, la idea de autorización (a terceros para que actúen en nombre propio) y la de transferencia de derechos son los fundamentos de la institución de la idea posterior de Estado, que apela al poder mediado por la razón para asegurar la paz y la justicia para todos. Además, dicho poder establece leyes específicas que definen patrones fijos de conducta, que son avalados a su vez con sanciones o penas, de tal forma que se garantiza que todos los individuos actúen en conformidad con las leyes.

Siguiendo a Hobbes, Max Weber diría luego que el concepto de Estado de derecho es una comunidad humana que, dentro de un territorio, reclama con éxito para ella misma en su totalidad, el monopolio de la fuerza física en conformidad con las leyes que entre todos han pactado como saludables para el bien público. (Carrillo, 2003, p. 147)

Posteriormente, Rousseau, con la idea del contrato social, busca preservar la igualdad entre los hombres, es decir, establecer roles y posiciones fijas entre los socios del contrato. Así, es posible llegar al bien común, siempre y cuando el pueblo y el soberano sean una misma persona, para ello es necesario un Gobierno democrático sabiamente moderado (Urquijo, 2002, p. 168).

Asimismo, este contrato social busca generar un espacio político donde los hombres puedan vivir libres e iguales, donde cada asociado esté protegido junto con sus bienes, asumiendo que los derechos y los deberes de los individuos constituyen las cláusulas del contrato social, y el Estado es la entidad creada para hacer cumplir el contrato. Es la posibilidad concreta que establece una comunidad política para equilibrar las desigualdades naturales que se presentan en el estado de naturaleza y así establecer un orden social.

Finalmente, teniendo en cuenta los elementos centrales de las apuestas teóricas de estos autores, se profundiza en la idea de acción política y cómo esta concepción es clave para entender más adelante la política y lo político.

Maquiavelo alude al ideal político de una sociedad bien ordenada y en El príncipe su preocupación es encontrar las estrategias más eficaces para reconstituir, en tiempos de crisis, el círculo virtuoso entre 
buenas leyes, soberanos que buscan el interés general y súbditos leales o solidarios con el bien común (Papacchini, 2000, p. 95). Sin embargo, concluye que el problema fundamental de la política es comprender cómo es posible mantener el poder del Estado en cabeza del soberano, y entiende que la violencia es un requisito ineludible para este propósito, lo que la convierte en una manifestación concreta de la acción política. Así, el enfrentamiento armado tiene un carácter instrumental "en función y al servicio de la política: el valor de unas armas eficientes y de un ejército propio resulta directamente vinculado con su capacidad de asegurar el vivir libre frente a posibilidad de invasiones y violencias externas" (Papacchini, 2000, p. 96).

Para Maquiavelo, la política tiene sus propias reglas, las cuales deben ser dominadas si se quiere alcanzar el fin que se busca. Por esto, la más importante propiedad de la acción política es la capacidad que debe tener el príncipe para alcanzar y mantener el éxito; capacidad que se alcanza mediante el dominio del poder de la fortuna por medio de la virtud (Cortés, 2003, p. 111). El hombre virtuoso es entonces aquel líder carismático que tiene a su favor los beneficios de la fortuna y su liderazgo es producto de la valentía o astucia para asumir su rol.

En función de esta tensión permanente del príncipe por mantener su poder y virtud, con el ánimo de garantizar una soberanía que mantenga a la comunidad política, Maquiavelo es reconocido por incluir en la discusión un realismo político separado de toda vinculación ética y moral, y estableció que "la ausencia de carácter moral es una condición de éxito de la acción política" (Cortés, 2003, p. 91).

Así, Maquiavelo profundizó en la descripción de la vida real del poder, pero no ahondó en la consideración de las instituciones que le darían legitimidad. La tradición renacentista, cuyo símbolo mayor es Maquiavelo, adopta a la república como el modelo de un régimen de libertad política indispensable para la construcción del Estado moderno, libertad entendida como autogobierno (Singer, 2002).

De esta forma, Maquiavelo se ocupa por develar las características que residen en los soberanos para asegurar el ejercicio del poder y liderazgo de una nación. Acude a una idea de política que se despoja de un andamiaje moral y se ocupa de garantizar el cumplimiento de las leyes a través de mecanismos como la violencia necesaria y las 
condiciones de soberanía en una comunidad que debe ser dominada y que no goza de un estatus de acción política entre los súbditos, sino de estricto cumplimiento del mandato soberano.

Por su parte, Hobbes posiciona la idea de que el poder político reside en un estamento artificial y fuerte como el Leviatán, que es soberano y legítimo, porque se instituye únicamente para proteger y defender los derechos inalienables de todos los individuos, lo que haría ociosa cualquier objeción o resistencia (Carrillo, 2003, p. 148). Es decir, desconoce y niega la posibilidad de disidencia por parte de los hombres.

Sin embargo, Hobbes es el primer filósofo moderno que articuló una teoría contractualista detallada, porque comprende el poder político a través de un contrato social celebrado libremente entre los hombres que deciden ceder sus derechos a cambio de protección y seguridad, que fundamenta las bases del poder de un agente externo, que es el Estado.

$\mathrm{El}$ argumento central de Hobbes es que en el estado de naturaleza, a diferencia de Aristóteles, no puede existir vida genuinamente política, porque lo político es precisamente el arte de instaurar la paz para proteger la vida humana; por el contrario, en el estado de naturaleza prima la confrontación permanente, la guerra de todos contra todos. En últimas, su idea de hombre se aleja de la apuesta del griego, pues para Hobbes el humano no es un animal político:

Lo político sólo podría surgir de una correcta deliberación de todos sobre lo que pueda ser bueno para todos y eso no está dado instintivamente. Es equívoca la expresión de zoon politikon -animal político-, porque una cosa es que los humanos vivan como pueden unos al lado de los otros, pero otra completamente distinta es si fueran capaces de organizarse políticamente. Lo político como formulación de normas que pudieran ordenar el ejercicio del máximo bien común sería para Hobbes la más elevada obra humana que, como magnífica obra de arte, pondría de manifiesto las más extraordinarias posibilidades de las que serían capaces los humanos. (Carrillo, 2003, p. 141)

De esta forma, se entiende que Hobbes asume lo político como una mediación externa a la acción humana, que se produce en el orden de 
lo colectivo y que es necesaria para mantener un orden que preserve la paz y la seguridad colectiva. Hobbes no profundiza en las condiciones de ese acuerdo, pues parte de un principio de igualdad que reside en todos los hombres, dado que las distancias entre unos y otros son producto de la convivencia y no de una distinción propia de la naturaleza humana. Por eso su interés se centra en el dominio de la fuerza y el poder que se le otorga al Leviatán, como una entidad extraordinaria que genera temor y obliga a todos los humanos que conviven en una nación a acatar las leyes y a mantener las condiciones de convivencia social. La política y lo político son un ámbito inseparable del ejercicio del poder soberano del Estado.

Por otro lado, Rousseau, con la idea del contrato social, sustenta la tesis de la voluntad general como legitimadora del poder político. En la búsqueda del establecimiento de una soberanía que nazca del propio pueblo y no que descienda sobre él a partir de alguna exterioridad exógena. Todo esto porque la libertad natural es una cuestión inalienable, que la constituye en condición imperativa fruto de ese acuerdo social, pues solo así el ciudadano puede participar en la construcción de las leyes para que exista una república, y de esta manera acentuar la necesidad de la participación social, justamente por la imposibilidad de la delegación legítima. El buen gobierno es el que emana del pueblo (Singer, 2002, p. 53).

De esta forma, a partir de Rousseau se establecen las condiciones para la existencia de un Estado moderno, donde la soberanía popular concuerde con el Gobierno de la república apelando a los acuerdos colectivos que fundan las condiciones de una vida social capaz de tramitar los conflictos y disputas a través de las leyes.

El valor del contrato social, como acuerdo de la mayoría y en defensa de la libertad, es una condición básica de lo que entendemos por la política como condición institucionalizante que tramita la convivencia humana y que determina los límites y alcances de la acción política de los gobernados en condiciones de libertad y autonomía, determinados por el establecimiento.

Finalmente, en este punto se hace explícita la vinculación permanente de los filósofos políticos consultados por entender la política a través de las complejas relaciones entre gobernados y Estado, como 
punto central de la constitución de comunidades políticas y de acción política limitada a la institucionalidad y a la soberanía de los Estados. Así, lo político es relativo a la política y se entiende como una sola categoría, sin distingo y supeditado a la creación de leyes que garanticen la vida en comunidad.

\section{Acción política como aparición, principio de lo político}

Desde otra perspectiva, Hanna Arendt afirma que la política se basa en el hecho de estar juntos, de la pluralidad de los hombres que se produce en la relación con los otros, condición que se configura como medio y fin para la convivencia y el aseguramiento de la vida en un sentido amplio. "La política se basa en la pluralidad de los hombres, es decir, en el entre nos, los unos con los otros y los diversos" (Arendt, 1993, p. 45).

$\mathrm{El}$ análisis de esta autora reconoce la política como Aristóteles la había entendido, para distinguir que la libertad era lo que diferenciaba la convivencia en la polis de otras formas de existencia humana. Arendt supone que lo político, en el sentido griego, se fundamenta en la posibilidad de establecer un espacio compartido socialmente por ciudadanos iguales y plurales. "La política, más que con la dominación se identifica con la libertad, entendida ésta como la capacidad de actuar en la urdimbre de relaciones humanas que conforman la esfera pública" (Uribe de Hincapié, 2003, p. 291). Este era el sentido de la política griega antigua, y desde esta lógica fundamenta su apuesta teórica, caracterizándola como una práctica que no es natural sino intencional, ya que se produce solo en la Polis, o sea, en el ámbito de lo público, ejercida por los ciudadanos libres $^{1}$ y que podía darse solo entre semejantes. Por lo tanto, el centro del ejercicio político es la libertad y la igualdad.

La libertad tiene que ver pues con la pluralidad, la cual es entendida como elemento constitutivo de la condición humana. Pero la pluralidad no es idéntica a simple alteridad (otherness), pluralidad

1 Para Arendt, la política como espacio de relación se constituye en la acción. 
tiene que ver con distinción, tiene que ver con lo que se muestra a través de la acción y del discurso. Con las cosas compartimos la alteridad - la curiosa calidad de alteritas que posee todo lo que es- pero la distinción es propia de la acción humana. En la medida en que pluralidad significa distinción, es posible la revelación —en el medio público — de la individualidad de cada uno, de la identidad (whoones). La acción como initium no es el comienzo de algo sino de alguien: con las palabras y con la acción nos insertamos en el mundo humano. Desde esta perspectiva, la política introducirá una ruptura en relación con cualquier modalidad simplemente social de vida: la pluralidad de los seres humanos, un mundo que se constituye en común, no es asimilable a la unidad homogénea del género humano. (Arendt, 1993, p. 20 y 21)

Para Arendt "sólo hay auténticos destellos de política cuando las personas se organizan para pensar y construir un mundo propio donde habitar en creativa libertad" (Estrada, 2007 p.153). Este espacio era para los griegos el ágora, donde los hombres libres eran capaces de abandonar el mundo privado para enfrentarse a sus pares. Por eso, la esfera pública se caracteriza por otorgar a los ciudadanos libres la igualdad propicia para la acción, la cual siempre está mediada por el discurso.

Arendt (1993): "por naturaleza los hombres no son iguales, necesitan de una institución política para llegar a serlo: las leyes. Sólo el acto político puede generar igualdad, sin embargo, las leyes no cumplen aquí la función de reducir lo diverso a lo idéntico e invariable, sino que autorizan la posibilidad de las palabras y las acciones" (p. 22). La clave entonces es la libertad y la igualdad, como productos de la acción política, a partir de la cual se generan las condiciones para las relaciones sociales, en las cuales se produce la vida activa, es decir, donde se establecen los acuerdos, valores y significados compartidos de la vida social.

Asimismo, la esfera pública está vinculada a la libertad y a la igualdad, la cual se produce en primera medida por la posibilidad de aparición de los sujetos en el ámbito de lo común, no solo en el mundo de la necesidad, y en segunda instancia por la acción y el discurso. A continuación, se explican a profundidad estos elementos. 
Existen tres dimensiones de la condición humana, la labor, el trabajo y la acción. Arendt entiende la labor como la dimensión ligada a la necesidad, al ciclo de repetición de la naturaleza; es decir, todas aquellas actividades que son necesarias para la sobrevivencia, razón por la cual es repetitiva, permanente y se circunscribe específicamente al ámbito de lo doméstico. El trabajo, por su parte, es productivo, dado que sus resultados están destinados, más que a ser consumidos, a ser usados, es decir, tienen un carácter duradero. El trabajo es la dimensión por medio de la cual se genera una variedad inagotable de cosas que constituyen el mundo donde vivimos, el artificio humano (1993, p. 17).

Los ciudadanos libres son aquellos que producen acción, y en Grecia este era el beneficio solo de aquellos hombres que tenían resuelta la vida cotidiana y se dedicaban al debate público. Es decir, solo la acción es política en la vida activa, porque es la única en la que existe la posibilidad de relación entre iguales, en oposición a aquellas actividades prepolíticas o apolíticas, referidas a la vida doméstica que impiden justamente el encuentro y la confrontación, como la labor y el trabajo. "Para ejercer la política hay que ser parte del mundo humano, y para esto se requiere ser espectador; ser pensador y relacionarse con otros" (Estrada, 2007, p. 153).

Sólo se es igual y libre en la Polis, porque en esa esfera los hombres no están sometidos a la necesidad, y sólo se consigue la igualdad cuando se aparece en público, cuando se abandona el mundo opaco del oikos y se vive entre iguales, es decir, cuando se es ciudadano. (Uribe de Hincapié, 2003, p. 296)

Así, el único lugar donde los ciudadanos libres pueden relacionarse políticamente y establecer el mundo compartido es en el ámbito de lo público, a través de la acción. Esto lo discutiré en otro capítulo, porque en las experiencias consultadas se devela otra posibilidad de acción. Para Arendt, los hombres no son sujetos previamente constituidos, sino singularidad que se establece de manera siempre dinámica y contingente al exponerse ante otros a través del discurso y la acción. La política como espacio de relación se constituye en la acción, y esta a su 
vez implica varios aspectos, que hacen de este un concepto complejo y fundamental para entender la propuesta arendtiana.

La acción es la actividad del hombre en cuanto hombre, lo cual quiere decir en su carácter plural (Estrada, 2007, p. 153), o sea, se presenta como una manifestación humana que permite la confrontación frente a los otros, o entre los hombres y su diversidad, que produce a la vez visibilidad en la esfera de lo público y la posibilidad de construir lo social. Por eso tiene implícito un carácter contingente y frágil, pero además se vale del discurso para su concreción o materialidad. Esto es:

La acción sin embargo, sólo es política si va acompañada de la palabra (lexis), del discurso. Y ello porque, en la medida en que siempre percibimos el mundo desde la distinta posición que ocupamos en él, sólo podemos experimentarlo como mundo común en el habla. Sólo hablando es posible comprender, desde todas las posiciones, cómo es realmente el mundo. El mundo es pues lo que está entre nosotros, lo que nos separa y nos une. (Arendt, 1993, p. 19)

Es decir, en el entre nos se produce el mundo, el cual solo se puede comprender desde el logos, a través del discurso, en la particularidad de cómo se da a cada uno de los hombres, cómo se presenta ante otros y en la discusión de cómo construir uno compartido. "La acción y la palabra convierte en significativa la praxis. Así, la palabra es entendida como una suerte de acción, como una vía para conferir sentido y durabilidad al mundo y para decir nuestra responsabilidad con respecto a él" (Arendt, 1993, p. 27). De este modo, la unión entre discurso y acción se entiende como posibilidad de manifestación en el mundo compartido.

La manifestación fractura el orden de lo visible y a la vez es revelación de los actores, exposición de las comunidades contestatarias y reinstitución continua de su espacio público de aparición. La manifestación confiere así a la acción política una dimensión fenoménica que se distancia de toda estrategia (relaciones de fuerza), de toda instrumentalidad (relación entre medios y fines) y de toda funcionalidad (relaciones de utilidad). (Tassin, 2012, p. 4) 
Por eso, la acción como aparición de la diversidad y posterior negociación, se produce en la libertad e igualdad, y no como consecuencia de tendencias o fuerzas ajenas al actor. Además, abre la posibilidad del antagonismo y la deliberación como el centro del espacio público, que genera la visibilidad de actores y apertura a configuraciones de realidad a través de la deliberación como ámbito esencial de la acción política. Por eso el actor emerge de la mutua exposición de la pluralidad actuante, aunque se dé un espacio, en todo caso, construido, que puede posibilitarlo en mayor o menor medida (Quintana, 2012, p. 53). En este sentido, introduce tres virtudes del actuar político:

La revelación de los actores en y por la acción y la palabra, la puesta en relación de los actores entre sí y la institución de un espacio del aparecer que se establece gracias al actuar juntos entre los actores y entre ellos y los espectadores, si se acepta que en una democracia, por principio, todo ciudadano es a su vez actor y espectador. (Tassin, 2012, p. 8)

A su vez, para Arendt la acción es contingente e imprevisible, porque las acciones humanas por su procedencia, son cambiantes, espontáneas, y a pesar de tener un comienzo definido nunca tienen un fin predecible, así que los actores no sospechan las consecuencias eventuales de una acción específica. Conscientes a su vez de que esta se vincula a un mundo que ya existía previamente, y que aunque la acción inaugure o devele algo que antes no existía, no es posible controlar los efectos, consecuencias o prever las transformaciones que produzca en el mundo. "La acción es frágil porque es un hombre el que la inicia, pero su continuación depende de mil hombres más que la interceptarán y la llevarán a desenlaces inimaginados o la conducirán a la nada simplemente con ignorarla" (Estrada, 2007, p. 147).

Lo que se sugiere es que la acción y el discurso son indeterminados por definición, y que a diferencia de la tradición filosófica que existió previamente a Arendt, la política no solo tiene que ver con el arte de gobernar o la configuración de un Estado, sino especialmente es sobre los hombres y la contingencia o capacidad de transformación que implica la construcción de un entre nos implícito en la condición 
humana, y es el rasgo esencial de la acción política, como un asunto público. "Los humanos sólo son libres mientras actúan, nunca antes ni después, porque ser libre y actuar es una y la misma cosa. Así pues, en política, lo que está en juego no es la vida sino el mundo, como espacio de aparición" (Arendt, 1993, p. 26).

Así, la acción con su capacidad creadora de sentido engendra poder como construcción humana de acuerdos, por cuanto "el poder sólo es realidad donde palabra y acto no se han separado, donde las palabras no están vacías y los hechos no son brutales, donde las palabras no se emplean para velar intenciones sino para descubrir realidades" (Arendt, 1974, p. 264). De esta manera, la acción permite a los hombres ocupar un espacio y llegar a transformarlo, y el lenguaje deja construir sentido y mundos posibles de acción, diferenciándolo de la violencia, que es privada y no produce nada diferente a coacción, dominio y exterminio de la libertad y los hombres (Estrada, 2007).

El vínculo entre acción política y contingencia es pues, en la propuesta arendtiana, uno de los elementos más significativos como apertura al concepto de lo político, pues le devuelve a la política el protagonismo de los hombres a través de la acción política como manifestación de la libertad y no de fines y medios, como se concibió tradicionalmente.

Suponer la acción como acontecimiento es contemplar la singularidad y contingencia de la condición humana que es producto de la libertad y las diversas posibilidades que las diferencias y las manifestaciones individuales tienen en un espacio compartido pluralmente.

Acontecimiento es lo que sobreviene o adviene en el tiempo humano. J. Taminiaux afirma que el acontecimiento es lo que, tanto para los individuos como para las colectividades, emerge a título singular e imprevisto en el tiempo, aparece con el tiempo notoriamente y merece ser conmemorado como tal. Sólo hay acontecimiento cuando se introduce sentido o, lo que es lo mismo, no hay acontecimiento sin mundo común; es decir, el acontecimiento es inseparable de la imprevisibilidad y de la fragilidad de la acción y de las palabras que vinculan a los individuos entre sí. (Arendt, 1993, p. 32) 
Esta concepción de acontecimiento vinculada a la acción se produce por su condición autónoma e imprevisible, que en su carácter instituyente de espacios de libertad, deliberación y visibilización de agentes se presenta como una irrupción. Asimismo, la acción es frágil, como se mencionó anteriormente, pues así como nace y puede establecer un campo de aparición de lo diferente, también puede evanescerse, como en el caso de las revoluciones. Así que la política desde esta apuesta se convierte en un reto que no se puede dar por sentado, sino que se construye permanentemente en la pluralidad humana "pues al manifestarse como acontecimiento, abre ella misma la posibilidad de su propia destrucción en la medida en que es incapaz de sostener el espacio público que inaugura” (Paredes, 2012, p. 43).

Dada su imprevisibilidad, no es posible condicionarla ni mantenerla sostenida en el tiempo; entonces, la acción arendtiana como acontecimiento, dado su carácter irruptivo y de aparición, transforma y hace visible en el ámbito de lo público agentes, sentidos y significaciones que antes no lo eran, y que dan cuenta de posibles nuevos órdenes o prácticas frente a un asunto colectivo que se constituye en el entre nos. "La acción no es el producto de la voluntad soberana de un sujeto, sino la irrupción performativa de la novedad en un mundo compartido" (Paredes, 2012, p. 43).

Con esto, Arendt genera una ruptura con las reflexiones tradicionales que hasta el momento se habían encargado de definir la política para los hombres, empezando con Platón, quien la consideró como un medio para asegurar la vida y así posibilitar a los hombres el hecho de dedicarse a la contemplación. De este modo, se entendió que la política estaba para posibilitar algo más: la filosofía primero, después las instituciones y finalmente la vida privada. La tradición de la filosofía política occidental ha considerado la política como medio para alcanzar la libertad, con lo cual se invierte la premisa aristotélica, en la que se necesitaba ser libre para ejercer la política (Estrada, 2007, p. 152).

Así, la política antes que ser un espacio dotado de contingencia, se entendió como un orden administrado por la fuerza y la violencia legítima que pretende neutralizar los riesgos de la pluralidad y generar gobernabilidad. 
Dado que el vínculo político no se asume como una trama que se teje en las acciones y palabras singulares de una pluralidad humana, sino como relación instrumental entre sujetos acomunados por objetivos similares. Así, al adoptar la lógica medios-fines, la política se convierte en medio para garantizar un cierto orden, para neutralizar el conflicto disponiendo de los medios para ello, mientras que el poder como potencialidad de la pluralidad para actuar en una empresa en común tiende a identificarse con la instrumentalidad de la violencia. En efecto la pretensión de reducir la pluralidad para neutralizar los conflictos dominándola implica también desde el punto de vista de Arendt, generar impotencia, disminuir la potencialidad de poder que solo puede emerger de la pluralidad humana y contrarrestar esa impotencia con el uso de la coacción y de la fuerza. (Quintana, 2012, p. 52)

Desde esta perspectiva, la política es ante todo gobierno y dominación, que se materializa en las leyes, como máxima de la pluralidad humana, a las cuales hay que someterse en aras de construir un poder legítimo e ilimitado que se justifica en el uso de la violencia. Arendt (1993) también se ocupa de hacer la distinción entre violencia y poder. "El poder es construcción de mundo y sólo lo instauran los hombres en conjunto mediante los acuerdos entre ellos. En cambio, la violencia, que es privada, a pesar de su poder de destrucción, no puede construir nada” (p. 166). La violencia entonces aniquila la posibilidad de acción política.

De este modo, el poder solo se constituye por medio de la relación entre diferentes agentes que forman una comunidad, es decir, la acción es política cuando produce poder: "el único factor material indispensable para la generación de poder es el vivir unido del pueblo. Sólo donde los hombres viven tan unidos que las potencialidades de la acción están siempre presentes, el poder puede permanecer con ellos, y la fundación de ciudades-estado [...] es el más importante prerrequisito material del poder" (Arendt, 1974, p. 265). Así, estas colectividades abren la posibilidad a la acción política como espacio de aparición y construcción de los agentes inmersos en tramas de relaciones del mundo común. Entonces, actuar es diferente de hacer, controlar, disponer y todo lo contrario de la violencia política, que considera legítimo 
reducir o eliminar el conflicto o las diferencias, en cuanto acontecimiento mismo en el que puede desplegarse la pluralidad, pues en el espacio público las decisiones no están determinadas ni tienen un contenido prefijado, lo cual le permite también constituirse como un espacio de tensiones siempre latentes.

La política puede ser un espacio de aparición donde unos y otros despliegan igualmente su pluralidad y se unen en una empresa común que emerge de la misma trama de relaciones que se teje entre ellos; un espacio en el que unos y otros muestran su potencialidad, el poder de sus palabras y sus acciones, como un puro medio sin fin alguno que con la luz del acontecimiento puede hacer visible, hacer aparecer y eventualmente, transformar el mundo-en-común. (Quintana, 2012, p. 51)

\section{Lo político como amigo/enemigo}

Es necesario reconocer que Arendt no hace una definición de lo político; sin embargo, al partir de los desarrollos posteriores de otros académicos que se inscriben en la apuesta desarrollada por esta filósofa alemana, se puede asumir que "todos los arendtianos hacen hincapié en el aspecto asociativo (el aspecto de actuar de común acuerdo o de actuar juntos), en el momento comunicativo que yace en la acción política como apertura al concepto de lo político, en contraposición con el aspecto disociativo de lo político que adquiere la tradición schmittiana" (Marchat, 2009, p. 61). A continuación, se profundiza en la apuesta de este jurista alemán.

Carl Schmitt es el primer pensador que le apuesta a comprender, desde una perspectiva filosófica, dos ámbitos vinculados y hasta ese momento equivalentes: la política y lo político. Este interés surge a partir de la reflexión que suscita en él la realidad que atraviesa la sociedad germana de comienzos de siglo xx, y sobre todo la política desde la crítica a un Estado débil que se configura en el centro instituyente de poder. Así, Schmit entiende que "lo político por sí mismo no acota un campo propio de la realidad, sino sólo un cierto grado de intensidad 
de la asociación o disociación de los hombres" (Jiménez, 2004, p. 20), que no puede ser olvidado, dado que este se configura como la raíz del conflicto y como una condición ontológica inasible.

Su acercamiento al concepto de lo político, como condición humana, introduce por primera vez la posibilidad de ubicar a los agentes en el plano de la unidad política legítima, es decir, el Estado, en relación con la contingencia y conflictividad presente en la condición humana, a partir de lo cual se produce el vínculo de la política. "A Schmitt le interesa el momento originario de la constitución de la unidad política del Estado, y buscar en él el elemento esencial que permita explicar cómo se forma y cómo se mantiene la identidad del Estado. Esto es, la esencia de lo político" (Agapito, 2008, p. 18).

De esta manera, el concepto de lo político es una dimensión filosófica, de carácter ontológica que desde su perspectiva se vincula a la relación amigo/enemigo, en correspondencia con el Estado. A pesar de esta limitación, la inclusión de este concepto permite una apertura que hoy, más que nunca, es pertinente seguir profundizado.

Es la política lo que en todo caso parece causar problemas a Schmitt, ya que si bien presiente a un Estado moribundo, se muestra sensible ante el hecho mítico de lo político fuera del tiempo y de lo mesurable, de tal forma que la pregunta que subyace a su concepto de lo político será en todo momento ¿quién determinará al enemigo, quién determinará la guerra, si el Estado ya no es capaz de hacerlo? (Jiménez, 2004, p. 16)

Así, la distinción de lo político surge en el plano de lo estatal, como una crítica a la homogenización social que presupone el contrato social en una perspectiva liberal. Sin embargo, para el Schimitt, esta unidad o identidad es necesaria para la institución de la sociedad, pero sabe que es imposible dicha homogeneidad; por lo tanto, sugiere que la base de la política debe ser un ordenamiento jurídico basado en criterios claros y con autoridad precisa a través de la constitución, como instrumento de formación del Estado. Con esto se garantiza una voluntad unitaria del pueblo que producirá una unidad política asumida como identidad, que es independiente de la moral 
y el derecho. "El Estado, o más genéricamente la soberanía, no puede basarse en una pluralidad de sujetos "soberanos" ya que produce la pérdida de autoridad del Estado. Por eso, recoge la necesidad de una limitación de la política como requisito esencial del Estado constitucional" (Agapito, 2008, p. 18).

Teniendo en cuenta de Hobbes, Schmith parte de la concepción radical del principio democrático, en el cual solo hay un soberano, debido al pacto de ceder el poder de cada hombre y someterse a dicha autoridad; de Rousseau, toma la idea de que la soberanía es invisible e indelegable (Agapito, 2008, p. 21). Para Schmitt, lo que se ubica en el principio de la unidad política del Estado es una decisión política.

Lo político se define así como una decisión constitutiva y polémica, pues a través de ella se definen o determinan los contenidos en torno a los cuales se va a configurar la identidad de un pueblo frente a otro. Se trata de una decisión de carácter público, en el sentido de que no tiene que ver con los sentimientos o intereses individuales o privados, sino con algo que funda una relación entre pueblos. Y es polémica porque con ella se establece lo político como relación amigo-enemigo, tanto hacia el exterior, en la relación con otros pueblos o Estados, como hacia el interior, frente a aquellos que no comparten o respetan la identidad concreta y específica del Estado. La función de lo político, de esa decisión originaria, es pues, la de agrupar al pueblo en torno a un determinado contenido fundamental, y defenderlo frente a los que no comparten esa identidad, ya procedan del exterior o del interior.

(Agapito, 2008, p. 22)

Así, lo político carece de un objeto determinado y se convierte en una característica de lo humano, por cuanto se estructura en la distinción amigo/enemigo y opera en todos los ámbitos, lo que produce agrupaciones o antagonismos entre los individuos. Lo político se define sin una referencia específica frente a algo; aparece como una relación que se caracteriza por su intensidad, pero a la vez por su carácter efímero. Sin embargo, esta primera mirada a lo político no 
se refiere a los sujetos plenos de autonomía, sino como miembros que configuran una unidad estatal, es decir, se trata del Estado, no de los hombres.

Schmitt señala que la conformación de la unidad política es sinónimo de construcción de identidad, en torno a la cual se unifica el pueblo, y que se valida en la relación con lo diverso, con la otredad, con un exterior constititutivo, como señalan después Laclau y Mouffe (2004). De ahí que la idea de lo político haya sido considerada como el momento fundante o ineludible de la unión de los hombres en la concepción del Estado y la política, como administración del poder.

La distinción amigo/enemigo, a partir de la cual Schmitt entiende lo político, tiene que ver justamente con la política como administradora de ese poder que tiende a consolidarse, en la medida en que se constituye una unidad política, homogénea, que niega o suprime la diferencia en el interior de dicha unidad.

Schmitt acepta como ineludible ese momento de violencia, y asume que la homogeneidad sólo puede mantenerse negando por la fuerza cualquier diferencia que surja del carácter histórico y distinto de los individuos de que se compone el pueblo. De aquí que la política se identifique sin más con la idea de poder. (Jiménez, 2004, p. 28)

El momento decisivo de lo político se define cuando el pueblo establece una unidad política como tal y puede identificarse frente a lo diferente, distinguiendo en adelante los enemigos o amigos de dicha unidad. Lo político entonces se entiende como "un fenómeno de identidad, que es condicionado por su alteración, por su otredad, como señala Schmitt al hacer énfasis en el enemigo, ya que es éste quien eventualmente se opone a un similar en el combate" (Jiménez, 2004, p. 24). Se refiere, pues, a la identificación de un enemigo político o público, que amenaza la identidad y que plantea la necesidad de la lucha, de la oposición, del conflicto para mantener la unidad soberana del Estado. 
A partir del conflicto entre identidades, se da el caso serio de lo político, que ha de definirse por el combate de la identidad, contra la alteridad de un enemigo que amenaza la propia existencia, por lo que, lo político se revela más bien en la autoafirmación colectivamente organizada de un pueblo políticamente existente contra los enemigos externos e internos. El combate tiene entonces un carácter decisivo en tanto en él se pone en juego la existencia. (Jiménez, 2004, p. 25 y 26)

La violencia es pertinente, en cuanto preserva la existencia de dicha unidad en la oposición que se presenta frente al enemigo o al conflicto. La guerra solo adquiere sentido en este espacio común o político donde igualmente se constata su límite, pues cumple la función de señalar el límite de la existencia, que es política. Es decir que para el autor la existencia humana tiene sentido solo dentro de una unidad o comunidad política, que se concreta en lo público. "Sólo a partir de este espacio se decide quién es el enemigo que representa la posibilidad combativa, y la contingencia de la guerra en tanto distintos, negación óntica de un ser distinto" (Jiménez, 2004, p. 28).

Así, se establece la necesidad de cancelar el conflicto interno en el Estado que debe ser absolutamente soberano. Por eso, la oposición se traslada solo al ámbito internacional, lo que determina la aparición potencial de la guerra, pues en el interior del pueblo existe un ordenamiento jurídico que garantiza la anulación del conflicto a partir de la existencia de la policía, o sea, la administración de la ley (Retamozo, 2009).

Los aportes más significativos del jurista alemán a la construcción de un concepto de lo político tiene que ver con lo siguiente:

El primero es el lugar del conflicto como constitutivo de lo político, el cual ha abierto importantes senderos a los pensadores posteriores; así, autores como Mouffe centraron su atención en este aspecto de lo político y dedicado esfuerzos considerables a salir de la lógica amigo-enemigo sin perder la dimensión conflictiva de la política. El segundo es el aporte al descubrimiento de lo político como un momento simbólico fundacional, originario, 
sin un contenido prefijado productor de un acontecimiento social potencialmente abierto y contingente. Esto implica reparar en el momento de la 'producción' de la distinción entre amigo y enemigo, vinculado a una decisión y, por ende, a una operación simbólica performativa de un campo. El tercero es el reconocimiento - junto a gran parte de la tradición germana- de la policía como esa lógica que busca la cancelación del conflicto dentro de un orden social particular, operando de esta manera en la (re) producción del mismo. (Retamozo, 2009, p. 73)

Teniendo en cuenta estos elementos, en adelante se busca precisar un poco más el concepto de lo político, tratando de articular las apuestas de Castoriadis, Laclau y Mouffe, y Rancière, destacando las características centrales de su andamiaje teórico y vinculándolas en función del proceso investigativo.

\section{Lo político como autonomía}

A partir del concepto de acción política, como la comprende Arendt, se puede entender la polis como el centro instituyente de las significaciones imaginarias sociales, en el sentido de Castoriadis, como esa posición que inaugura e instituye a los individuos y, por ende, a las sociedades; es decir, a las instituciones, a los agentes y las condiciones sociohistóricas que determinan esas relaciones.

La sociedad es obra del imaginario instituyente. Los individuos están hechos por la sociedad, al mismo tiempo que hacen y rehacen cada vez la sociedad instituida: en un sentido, ellos sí son sociedad. Los dos polos irreductibles son el imaginario radical instituyente - e1 campo de creación socio-histórico-, por una parte, y la psique singular, por otra. (Castoriadis, 1997, p. 2)

Para este autor, la institución de la sociedad es una obra humana, que se originó en Grecia a partir de la creación de la verdad como movimiento interminable del pensamiento, encabezada por los ciudadanos de la polis, quienes se ocuparon de la reflexividad de la 
vida en sociedad, las representaciones y las normas específicas para esa realidad.

Tanto la política griega como la política kata ton orthon logon pueden ser definidas como la actividad colectiva explícita queriendo ser lúcida (reflexiva y deliberativa), dándose como objeto la institución de la sociedad como tal. Así pues, supone una puesta al día, ciertamente parcial, del instituyente en persona [...]. La creación de la política tiene lugar debido a que la institución dada de la sociedad es puesta en duda como tal y en sus diferentes aspectos y dimensiones (lo que permite descubrir rápidamente, explicitar, pero también articular de una manera distinta la solidaridad), a partir de que una relación otra, inédita hasta entonces, que se crea entre el instituyente y el instituido. (Castoriadis, 1997, p. 9)

Así, la política se encarga de generar las relaciones y mediaciones entre los agentes y el mundo, es decir, el sentido de realidad y verdad, a partir de lo que el autor denomina el imaginario radical instituyente, que produce dos elementos fundantes de las relaciones y ordenamientos de la vida pública y privada: el instituyente y el instituido.

Estas dos formas que se afectan dialécticamente se pueden observar en dos niveles de implicación de la institución, uno social, a partir de los espacios de socialización donde el conjunto de las instituciones impregnan de sentido al agente, y un nivel psíquico, donde el individuo se constituye a partir de la información y el sentido ofrecido por las instituciones; "el individuo social se constituye interiorizando el mundo y las significaciones creadas por la sociedad, interiorizando de este modo explícitamente fragmentos importantes e implícitamente su totalidad virtual por los 're-envíos' interminables que ligan magmáticamente cada fragmento de este mundo a los otros" (Castoriadis, 1997, p. 3).

Aparece entonces la pregunta: ¿cómo surgen los agentes sociales?, ¿cuándo el agente empieza a reflexionar sobre su propia existencia, a partir de lo que la institución ha determinado para sí? Castoriadis advierte que una cuestión de poder, en la cual este es instituido por la sociedad, acciona y produce en el agente unos parámetros para actuar, que se producen a lo largo del contexto histórico-social de una 
nación y que se manifiesta también en cada uno de los agentes que constituyen la sociedad.

Partiendo de la concepción de la política como se ha desarrollado hasta acá, en el agente hay un infrapoder que permite la movilidad y autonomía, lo cual dinamiza la sociedad, genera tensiones y necesariamente transformaciones. Entonces, lo político se constituye como ese tránsito entre la tensión interminable entre el poder del instituyente y el instituido.

Esta dimensión de la institución de la sociedad, relacionada con el poder explícito, o bien debido a la existencia de instancias que puedan emitir imperativos sancionables, es a lo que hay que identificar como la dimensión de lo político. A este respecto, importa poco que estas instancias se encarnen en la tribu entera, en los ancianos, en los guerreros, en el jefe, en el démos, en el aparato burocrático o en lo que sea. (Castoriadis, 1997, p. 7)

Es decir, lo político se establece no solo en el ámbito de lo público como transferencia del poder, sino que también opera en los procesos de fundación de la realidad social de los agentes y de los comportamientos o relaciones intersubjetivas que se establecen en su ámbito de existencia.

Lo político es una de las características que fundamenta la esencia humana, en tanto, el hombre es un sujeto activo a partir de su dimensión política; es decir, a partir de su desempeño en la polis, partiendo de unas relaciones que lo instituyen como sujeto de acción, pero también que se modela en un ejercicio cognitivo de apropiación del orden establecido y que se reconfigura en relación con los otros y con las condiciones en las que se producen dichas interacciones.

Tratar de explicar el comportamiento político como un fenómeno exclusivamente psicológico o exclusivamente sociológico, excluye la posibilidad de comprender, en un horizonte transdisciplinar, los elementos culturales, históricos, económicos, jurídicos, entre otros, que se hallan vinculados a la noción de sujeto político y a las prácticas políticas que lo definen. En consecuencia, lo político debe ser comprendido como una realidad que se expresa y adquiere forma 
en el ámbito público, en el terreno de lo colectivo, del "nosotros”, pero está significado por el "mí mismo", cargado de los sentidos instituyentes de la esfera privada. (Alvarado et al., 2010, p. 245)

Así, lo político se constituye en un sentido polisémico que advierte no solo las condiciones materiales y simbólicas a partir de las cuales se estructura la sociedad, sino que se enmarca también en los ejercicios individuales (pero construidos en la intersubjetividad), a partir de los cuales se interiorizan los acuerdos instituidos y los sentidos de lo público, de la moral, del deber ser y de las posibilidades de acción con las que se constituye el agente.

Acá es importante hacer dos precisiones frente a la vinculación entre lo político y la política desde la apuesta de Castoriadis. En primera instancia, el poder explícito, como dimensión de la institución de la sociedad, vinculado a "instancias que puedan emitir imperativos sancionables" (1997, p. 7), no se sujeta solamente al Estado (institución secundaria), sino que opera y pertenece al conjunto de los ciudadanos.

La segunda precisión está referida a que la política produce las relaciones entre poder explícito y la institución conjunta de la sociedad, pero no los sustituye. Los griegos, para Castoriadis, crearon la política, pero no lo político en el sentido de la dimensión del poder explícito siempre presente en toda sociedad; no obstante, les atribuye la reflexividad como la primera aparición histórica del proyecto de autonomía colectiva e individual.

Los griegos crean la verdad como movimiento interminable del pensamiento, poniendo constantemente a prueba sus límites y volviendo sobre sí mismos (reflexividad) y la crean como filosofía democrática: pensar no es la ocupación de los rabinos, los curas, etc., sino de los ciudadanos que quieren discutir en un espacio público creado por este mismo movimiento. (Castoriadis, 1997, p. 8)

Para Castoriadis, la búsqueda de autonomía se convierte en una de las característica básicas de lo político, entendida como "auto-romos (darse) uno mismo sus leyes [...] Aparición de un eidos nuevo en la historia del ser: un tipo de ser que se da a sí mismo, reflexivamente, sus 
leyes de ser" (1997, p. 11). O sea, la autonomía es el actuar reflexivo de una razón que se crea en un movimiento interminable, que es social e individual a la vez y que afecta no solo el pensar y el hecho de interrogarse, sino también el hacer y el instituir; porque se convierte en una tensión permanente entre el ámbito interno y externo de los agentes, lo cual necesariamente afecta su desempeño en la sociedad. Este aspecto se desarrollará más adelante, como parte del análisis a las experiencias consultadas.

Desde esta perspectiva, la autonomía es una condición que activa el infrapoder de cada agente y que pone de manifiesto la tensión recíproca y permanente entre instituyente e instituido; de esta manera, configura lo político como una construcción dinámica de poder explícito, que produce transformaciones en el ámbito simbólico, material y significante de la sociedad. Su ámbito de producción se ubica en los intersticios de lo público, lo privado y en el acontecer espacio-temporal de las relaciones sociales, las cuales tienen una incidencia en el ideal de justicia de una sociedad.

Una sociedad justa no es una sociedad que adopta, definitivamente leyes justas. Una sociedad justa es una sociedad donde la cuestión de la justicia se mantiene abierta constantemente, dicho de otro modo, donde existe siempre la posibilidad socialmente efectiva de interrogarse a propósito de la ley y de su fundamento. He aquí una manera distinta de decir que se encuentra constantemente envuelta en el movimiento de su auto-institución explícita. (Castoriadis, 2000, p. 50)

Asimismo, la autonomía, como manifestación concreta del poder de los agentes, se construye en el plano de lo individual (subjetividad) y de lo colectivo (identidad), a partir de complejos procesos comunicativos que median la cotidianidad. En el caso de los y las jóvenes, dichos procesos se manifiestan sobre todo por vías no tradicionales, como las manifestaciones estéticas como acción política contingente que se determina por el tipo de individuos y sus orientaciones (conocimientos, creencias, valoraciones y sentimientos) frente a lo público, 
fruto de las múltiples tramas, relaciones o tensiones en las que se ubican (Contreras, Correa y García, 2005).

\section{Lo político como antagonismo y potencia desfijadora de sentido}

Para Ernesto Laclau, lo político se produce como punto fundante de lo social, como horizonte político de su institución. Sin embargo, hay que hacer algunas precisiones antes de profundizar en el concepto de lo político para este filósofo argentino.

Las relaciones sociales se configuran en el lenguaje y en la significación. "Toda relación social es una relación de significación. El campo de la significación y el campo de la sociedad pasan a ser términos equivalentes" (Laclau, 2002, p. 71). Por eso sus reflexiones asumen la comprensión de lo discursivo como un sistema de organización de lo social, que le permite, desde el estudio a profundidad de elementos lingüísticos y extralingüísticos, establecer un andamiaje teórico de las relaciones sociales, como estructuras discursivas en un contexto específico de significación social.

Lo social entonces se produce en el ámbito de lo discursivo y no se configura como una totalidad dada o establecida completamente o como un sistema cerrado, dado que tiene implícito un principio de significación permanente que convierte a la sociedad en una "imposibilidad productiva” (Marchat, 2009, p. 182). Así, lo social se estructura gracias a un movimiento constante de fijación/desfijación de sentido, desde el ámbito de lo discursivo, lo cual aduce que entenderla como totalidad es una condición imposible. Es justamente esta característica la que permite asumir lo social como una condición de posibilidad y de construcción permanente de sentido que se va configurando en el entre nos, como un terreno donde el sentido se fija parcialmente y no es definitivo. La sociedad entonces es imposible y necesaria a la vez, dada su infinitud.

Laclau propone, pues, pensar lo social como el terreno de las prácticas discursivas sedimentadas. Lo político en cambio, se define 
como el momento de la institución de lo social y, asimismo, como el momento de la reactivación de la naturaleza contingente de cada institución. Al apuntar a la naturaleza contingente de lo social, lo político interviene y deja claro que lo social no puede sustentarse en un fundamento estable. De ahí que lo político señale el fundamento ausente de lo social, y al mismo tiempo, sustituya esa ausencia (re)fundando esto último. (Marchat, 2009, p. 185)

La preocupación de Laclau reside en establecer las diferencias y alcances de lo político en relación con lo social, más que con la política, pues esta se produce justamente en ese ámbito de construcción colectiva del sentido, en la institución de este. "Siempre hay política, precisamente porque existe este desajuste estructural, que como hemos visto, está en la lógica de toda tensión entre el objeto que se trata de constituir y la imposibilidad última de constituirlo" (Laclau, 2002, p. 87).

De esta manera, la relación entre lo político y lo social, aunque diferencial, es complementaria, porque si bien el momento de lo político es justamente aquel de reactivación de las prácticas y el sentido de estas en un contexto específico, lo social como dominio de las prácticas sedimentadas se produce justamente en ese tránsito interminable de resignificación del orden social y el discurso, como expresión de la significación. "Por ese motivo, Laclau habla de la primacía de lo político sobre lo social (1990, p. 33). Lo social debe concebirse entonces como un tipo de 'modo dormido' de lo político y podemos imaginar que dondequiera que miremos, descubriremos lo político en la raíz misma de las relaciones sociales" (Marchat, 2009, p. 197 y 198).

Para Laclau, la sedimentación de las prácticas (desde Husserl) es la rutinización y olvido de los orígenes; así, en cuanto un sentido se ha institucionalizado, se desvanece socialmente el origen de este y se asume como presencia objetiva, por eso lo político recobra importancia como momento fundante de la reactivación de sentido, bien sea por la fijación o la desfijación que articulan las relaciones sociales, y que permite visibilizar los actos de institucionalización de sentido.

De esta forma, la esencia de lo político devela dos elementos constitutivos: en primera instancia, su estrecha relación entre discurso, significación y política, en cuanto se ubica en el momento de producción 
o resignificación social de cadenas significantes, que le dan fundamento a la política desde una lógica de la articulación permanente.

Desde el lenguaje es posible comprenderlo como un proceso permanente de politización: cada vez, que un elemento diferencial es incorporado en una cadena significante, la política misma de ese acto permite comprender la reactivación y la re-significación como proceso de politización. En concreto, politización es enunciación, en el plexo de una cadena significante, de una particularidad que se encontraba privada de audibilidad y/o discurso (que implica visibilidad). Sin embargo, este mismo proceso de articulación puede ser entendido como traducción; una traducción en la que el elemento diferencial pre-hegemonizado es dicho - traducido- según las coordenadas enunciativas de la cadena significante de la hegemonía. (Villalobos, 2002, p. 22)

En segunda instancia, como fruto de lo anterior, lo político adquiere un carácter fundacional, ontológico de la política misma (Villalobos, 2002), que en cuanto práctica se produce no solo en la estructura, sino también en las relaciones sociales de los agentes que se producen necesariamente, en la contingencia.

Laclau advierte que ese momento de contingencia no se debe asumir como accidentalidad o puro azar; por el contrario, las condiciones de un sistema son contingentes por cuanto no pueden ser derivadas de la lógica interna o de la racionalidad del sistema a las que pertenecen. En este sentido, la contingencia es producto de la interacción de los agentes, y entre estos el sistema y los regímenes de significación instituidos.

El momento de lo social es el momento de la sedimentación; y el momento de la reactivación sería el momento de mostrar la contingencia originaria, a través de la cual, secciones de lo social se han constituido. La contingencia originaria se muestra, pienso, solamente cuando hay relación entre fuerzas antagónicas, por eso creo que hay política cuando hay dislocación. Más precisamente, hay política cuando hay de un lado, dislocación y de otro lado, 
reinscripción, es decir, especialización o hegemonización de esa dislocación. (Laclau, 2002, p. 139)

Así las cosas, lo político se puede entender como un momento de resignificación de lo social, pero a través del antagonismo y la dislocación de la política. A continuación se explicitarán estos dos elementos centrales en la apuesta de este filósofo argentino. El antagonismo es el aporte central de Laclau y Mouffe a la concepción de lo político, pues es solo a través de las relaciones antagónicas que se asegura la posibilidad misma de la política.

Para tal fin, Laclau y Mouffe se ocupan de entender el antagonismo desde un recorrido a través de la noción dialéctica de contradicción de Kant, hacia la especificación de las diferencias entre contradicción lógica, oposición real y antagonismo social. Este último se confirma como el producto de unos determinados agenciamientos discursivos, que tienen la finalidad de establecer los límites de lo social, es decir, de hacer manifiestas las diferencias, las identidades en juego y los límites de lo que no se ha instituido o de lo que está por fuera de dicho sistema y que aún no se hace visible.

El antagonismo establece el límite de lo social. Dicho límite se caracteriza, además, por ser interno a lo social, dado que si separa simplemente dos territorios (=límite externo) constituiría una nueva diferencia: "La sociedad nunca logra totalmente ser una sociedad porque en ella todo está penetrado por sus límites, los cuales le impiden constituirse como una realidad objetiva". (Marchat, 2009, p. 187)

Así, las relaciones antagónicas develan que la idea de lo social como objetividad deja de ser un fundamento último pero real, que se revela siempre como una objetividad precaria y vacilante, que le impide constituirse definitivamente como sistema fundado. Lo político, a través de su carácter antagónico, permite hacer visibles los límites de toda objetividad.

Los antagonismos no son relaciones objetivas, sino relaciones que revelan los límites de toda objetividad. La sociedad está constituida alrededor de estos límites, y ellos son límites antagónicos. Y la noción de límite antagónico tiene que ser concebida literalmente es decir, 
no hay una "astucia de la razón" que le permita a esta percatarse de sí mismo, a través de estas relaciones antagónicas. Ni tampoco hay una especie de metajuego que subordinaría los antagonismos a su sistema de reglas. Es por eso que nosotros concebimos la política no como una superestructura, sino que ya teniendo el estatus de una ontología de lo social. (Laclau, y Mouffe, 2004, p. 18)

Así, suponer a las relaciones antagónicas como elemento central de lo político es entender que estas permiten visibilizar determinados agenciamientos discursivos, que hacen parte de la cadena de significantes que articulan, definen o instituyen lo social. Al hacer visibles y comprensibles los límites de dichas enunciaciones o posibles relaciones, cabe la posibilidad de resignificar e incorporar nuevas fronteras y sentidos frente a lo social, que movilicen, amplíen o incorporen nuevos significantes sociales, actores, identidades u otras formas de hacer, imaginar y producir la política. En últimas, se pude entender a las relaciones antagónicas como prácticas de lo político que visibilizan y confrontan los límites para la enunciación e institución de lo social, desde la contingencia. Este elemento se desarrolla más adelante, a la luz de las experiencias analizadas.

La enunciación de un conflicto es ya su configuración significante y esto podría funcionar perfectamente como desactivación de sus potencialidades de lucha, o bien podría funcionar como producción de un antagonismo. En este caso, la simple irrupción de un evento dislocante para el orden del discurso, no constituye necesariamente, su des-articulación, y de producir una desarticulación del orden discursivo hegemónico todavía habría que destacar el rol fundamental que tiene la re-inscripción (discursiva, alternativa, contra hegemónica) de dicho evento. El paso de la dislocación a la re-inscripción puede ser, precisamente, el momento de constitución del antagonismo, es decir, puede ser el momento de emergencia de la lucha contra-hegemónica. (Villalobos, 2002, p. 28)

De ahí la importancia para Laclau de constituir discursivamente a los antagonismos como diferencias específicas, que dan cuenta de los 
límites o fronteras que no permiten visibilizar las identidades o contradicciones profundas que subyacen a las equivalencias de lo social, y que al existir como manifestación de lo político, es decir, como reactivación de los sedimentos espaciales, generan una ruptura, alteración o interrupción de lo social como algo dado, y a cambio introducen la posibilidad del acontecimiento y de resignificación del mismo sistema. Laclau entiende este proceso como dislocación.

La dislocación como tal opera, en primer lugar, como un concepto límite negativo cuya función es indicar que no habrá nunca un sistema enteramente cerrado o una estructura significativa eternamente estable. La cuestión reside en que, cuando nos encontramos con la dislocación en nuestra experiencia social, ya la hemos construido de cierta manera. La dislocación ocurrirá siempre dentro del horizonte del ser, de lo social [...] Pero ello no significa que el momento políticamente instituyente olvidado de estas sedimentaciones desaparezca sin dejar huellas, pues sólo permanecerá olvidado hasta que retorne bajo la forma de antagonismo. (Marchat, 2009, p. 198 у 199)

Así pues, se configura la idea de que lo social como sistema cerrado es una imposibilidad, al igual que la apertura total, y que dada esta condición las relaciones antagónicas, como manifestación ontológica de lo político, permiten articular a las formas sedimentadas de objetividad que producen lo social otros límites, fronteras y regímenes de significación frente a los actos de institución política, como un acontecimiento que disloca y reconfigura lo social, en un proceso interminable de visibilización y articulación de lógicas de contradicciones y equivalencias que acompañan los procesos de significación.

\section{La potencia de la estética como dispositivo de enunciación de lo político}

Jacques Rancière ubica a la estética en la base misma del estatuto de la política. Para entender su apuesta, es necesario atender las críticas que formula a las concepciones teóricas "clásicas" a partir de las cuales se 
ha definido la política, para posteriormente contribuir a una concepción de lo político como ampliación del campo de significación y deconstrucción del orden de lo sensible que distribuye y organiza lo social.

En este sentido, el autor llama la atención sobre cómo desde las reflexiones teóricas de los clásicos se ha comprendido que "la política no es asunto de vínculos entre los individuos y de relaciones entre éstos y la comunidad, compete a una cuenta de las "partes" de la comunidad, la cual es siempre una falsa cuenta, una doble cuenta o una cuenta errónea" (Rancière, 1996, p. 19). Es una cuenta que se basa en criterios contradictorios; por ejemplo, Platón y Aristóteles afirman que la política es el ejercicio de hombres libres, pero está claro que la libertad en Atenas era privilegio de unos cuantos, de aquellos que tenían los recursos y el linaje para ello, no era una condición del pueblo en general. Sin embargo, la democracia se instauró como el modelo político que se basa en la libertad y en la justicia como fundamento.

La cuenta errónea a la que se refiere el autor es a suponer que los esclavos, las mujeres, los artesanos, o aquellos que no podían participar en el ágora, eran partícipes de los actos públicos o los momentos decisorios que constituían el ejercicio político. Es decir, lo público como asunto de la política era privilegio de unos cuantos, que legislaban o discutían y que tenían la areté en "beneficio" de aquellos que no estaban capacitados para hacerlo. Esto genera una cuenta errónea para el autor, pues da cuenta del "nudo originario del hecho y el derecho y la relación singular que establece entre dos palabras clave de la política, la igualdad y la libertad” (Rancière, 1996, p. 21).

Así, el pueblo carente de posibilidades reales de inclusión en los asuntos públicos fue asumido por los dirigentes virtuosos como el centro del ejercicio político, a través de la libertad (como concepto contradictorio en las prácticas) y la justicia, como máxima que les permitiría a los que no tienen parte vivir en comunidad.

El demos es la mayoría en lugar de la asamblea, la asamblea en lugar de la comunidad, los pobres en nombre de la ciudad [...]. Pero todas estas manifestaciones de desigualdad del pueblo consigo mismo no son más que las monedas sueltas de una cuenta errónea fundamental: esa imposible igualdad de lo múltiple y el todo que 
produce la apropiación de la libertad como propia del pueblo. Esta imposible igualdad arruina en cadena toda la deducción de las partes y los títulos que constituyen la ciudad. (Rancière, 1996, p. 24)

Esta cuenta errónea de la que habla Rancière se produce por una máxima que se ubica en el discurso de los clásicos y que prevalece hasta nuestros días. La política es un ejercicio mediado por el logos, entendido desde la argumentación y la estructura del pensamiento racional que se considera el centro del ejercicio político y una característica de la condición humana.

El destino supremamente político del hombre queda atestiguado por un indicio: la posesión del logos, es decir de la palabra, que manifiesta, en tanto la voz simplemente indica. Lo que manifiesta la palabra, lo que hace evidente para una comunidad de sujetos que la escuchan, es lo útil y lo nocivo y, en consecuencia, lo justo y lo injusto. La posesión de este órgano de manifestación marca la separación entre dos clases de animales como diferencia de dos maneras de tener parte en lo sensible: la del placer y el sufrimiento, común a todos los animales dotados de voz; y la del bien y el mal, propia únicamente de los hombres y presente ya en la percepción de lo útil y lo nocivo. Por ello se funda no la exclusividad de la politicidad, sino una politicidad de un tipo superior que se lleva a cabo en la familia y en la ciudad. (Rancière, 1996, p. 14)

Sin embargo, esta distinción entre logos y phoné permitió establecer un abismo que no solo se reduce entre la distinción entre una queja o un gemido, sino que instauró unas formas del decir, excluyó otras y determinó quiénes tienen la palabra y quiénes voz; esto produjo unos ordenamientos y límites del sentido que no involucran a todos los agentes sociales, y que en aras de un orden consensual excluye, limita y normaliza los regímenes de significación y las posibilidades del nombrar y del hacer en el ámbito de lo común.

Esta distinción radical fundamentó a la política, se estableció una ordenación de espacios y de cuerpos que ubicó a hombres dotados de logos y a seres parlantes que están dotados solo de voz (phoné). "La 
voz, dice Aristóteles, es un instrumento destinado a un fin limitado. En general, sirve para que los animales indiquen (semainein) su sensación de dolor o de agrado" (Rancière, 1996, p. 35). Así, el ámbito de lo público está configurado desde la razón del logos, de una razón ilustrada que implica unas lógicas de enunciación y argumentación a partir de las cuales se dirime lo justo, lo útil y lo real. Aquellos que están limitados a la voz, en cambio, fueron arrojados al ámbito de lo privado, de la oscuridad y la sombra; fueron privados de inscripción simbólica en la ciudad, todo lo contrario al ágora.

Esta distribución o reparto simbólico de los cuerpos y sus prácticas es fundamental para comprender la lógica del logos que determina la política como un ámbito de visibilidad de agentes que poseen una palabra que es válida en la configuración de lo común y aquellos cuya voz solo imita la voz articulada.

Hay política porque el logos nunca es meramente la palabra, porque siempre es indisolublemente la cuenta en que se tiene esa palabra: la cuenta por la cual una emisión sonora es entendida como palabra, apta para enunciar lo justo mientras que otra sólo se percibe como ruido que señala placer o dolor, aceptación o revuelta. (Rancière, 1996, p. 37)

A partir de esta distinción Rancière ubica dos lógicas problemáticas que determinan a la política. Por un lado, ese registro permanente que busca normalizar y mantener el orden o reparto de lo sensible que precisa las formas y posibilidades de visibilidad de los agentes, es decir, la distribución sensible de los cuerpos en comunidad; para el filósofo francés esta es la policía, y la política como ese espacio contingente que abre la posibilidad de verificación de la igualdad, a partir del litigio y el disenso, en contradicción permanente con la policía.

Así, la policía se instituye como una forma particular de un orden general, que está implícita en la comunidad y que se materializa en las leyes, en la distribución de lugares, formas y funciones a partir de lo cual se produce lo social. Desde esta mirada policial, se establecen unas lógicas de argumentación y visibilidad que resultan arbitrarias para todos los seres parlantes; por eso, la tensión entre ese desacuerdo 
y ese orden policial es permanente, lo cual configura a la política como el ámbito de aparición sensible de la experiencia (Escudero, 2009).

En cambio, la acción política es una manifestación contingente que problematiza las divisiones sensibles que establece el orden policial, que deja en evidencia la visibilización de una parte de los que no tienen parte, y que tiene como intención verificar ese principio de igualdad entre seres parlantes. Es decir, la política tiene que ver con las formas de visibilidad y ordenamientos que se establecen en una comunidad, con la distribución de las partes de la comunidad y con las prácticas de verificación de la igualdad, desde prácticas de emancipación y de desacuerdo. "El vínculo entre estos dos argumentos se arma en "la partición de lo sensible" y en la existencia del litigio respecto de esa partición, del reparto del común de la comunidad" (Escudero, 2009, p. 28).

La política es aparición e institución, es una forma específica de vínculo que busca la interrupción de las lógicas y ordenamientos policiales de la comunidad como comunidad política y que implica el despliegue de una distorsión de dicha comunidad, la cual nunca terminará de configurarse como un organismo cerrado. Así, "la distorsión no es simplemente la lucha de clases, la disensión interna que debe corregirse dando a la ciudad su principio de unidad, fundándola sobre la arkhé de la comunidad. En la política se refleja la imposibilidad misma de la arkhé" (Rancière, 1996, p. 28). La política entonces se configura como una forma de interrupción del orden policial que funda comunidad y que tiene implícito el principio de verificación de la igualdad de cualquiera con cualquiera, y que busca instituir órdenes contingentes y litigiosos, dado el principio dinámico de lo social.

El autor presupone que el principio de universalidad de la política reside en su implementación discursiva y práctica, que se construye en el discurso y en la práctica con la intención de invocar, presuponer, verificar o demostrar el principio de igualdad como un operador de demostraciones. "La universalidad política no está en un hombre o en ciudadano. Está en el ¿qué es lo que resulta de eso?, en su implementación discursiva y práctica" (Rancière, 2006, p. 20).

La acción política se ubica así como una puesta en evidencia de la ausencia de fundamentos en el reparto de lo sensible, como una forma de enunciación que advierte oposición frente a esa distribución 
arbitraria de discursos, roles y prácticas vinculadas a esos roles, en el ámbito de lo común. Es una demarcación de los agentes respecto de ciertos espacios de enunciación dados, correspondientes a diversos modos de ser-hacer.

Tal movimiento se entiende en términos de acción política, en la medida en que implica un cuestionamiento de los modos de experiencia existentes, determinados por una cierta partición de lo sensible y reproducidos por la lógica policial, es decir, por un modo anterior de enunciar y hacer visibles las maneras de hacer de la comunidad (Escudero, 2009, p. 33)

Así las cosas, la política es un asunto de sujetos y de modos de subjetivación, que devela una multiplicidad que no es tenida en cuenta en la constitución policial de la comunidad, como un proceso de desidentificación o desclasificación frente a la naturalidad de un lugar que asignó la lógica policial, es la apertura de un espacio otro al sujeto. "El tomar la palabra no es conciencia y expresión de un sí mismo que afirma lo propio. Es ocupación de un lugar donde el logos define otra naturaleza que la phoné" (Rancière, 1996, p. 53).

La subjetivación política recorta el campo de la experiencia que daba a cada sujeto su identidad con su parte.

Deshace y recompone las relaciones entre los modos del hacer, los modos del ser y los modos del decir que definen la organización sensible de la comunidad, las relaciones entre los espacios donde se hace tal cosa y aquellos donde se hace tal otra, las capacidades vinculadas a ese hacer y las que son exigidas por otro. (Rancière, 1996, p. 58)

Lo político entonces es un campo problemático de litigio o disenso en el orden consensual, en cuanto se configura como un espacio de enunciación, de manifestación de la subjetividad que busca hacer posible la emancipación, como un juego de prácticas guiadas por la presuposición de igualdad de cualquiera con cualquiera y de la preocupación por verificarla en medio de la lógica policial. "Lo político será el terreno del encuentro entre la emancipación y la policía en el tratamiento de un daño" (Rancière, 2006, p. 18.) 
Lo político es la constitución de un escenario de puesta en litigio que busca incluir otros regímenes de significación que podrían eventualmente producir otra división de lo sensible. Es también un ámbito de lo contradictorio, de lo polémico, que busca alterar referentes compartidos que terminan implicando otros sentidos y posibilidades de enunciación. Es la apertura, desde el régimen de lo policial, a otra forma de experiencia y acontecimiento de un sujeto, que comprueba en este intervalo de aparición la posibilidad de escritura o reescritura de sentido, a partir de la reorganización de los signos de otro modo. A partir de la interrupción y creación de escenarios de litigio o disenso, lo político se devela como una apuesta de desidentificación de sentido que produce una nueva configuración de lo sensible; no solo como inversión de las posiciones, sino también como posibilidad de cuestionar ese fijamiento y el condicionamiento de un accionar específico atribuido al orden de lo sensible, que permite una disociación de los agentes y una reconfiguración de capacidades que producen torsiones o transformaciones en las formas de experiencia política.

Una de las posibilidades de enunciación más fructíferas para Rancière es a través de la estética —en un sentido amplio—, la cual facilita oportunidades de litigio que interrumpan los regímenes de significación y que produzca otros sentidos, visibilidades e irrupciones a las lógicas de la razón consensual. "Lo que constituye el carácter político de una acción no es su objeto o el lugar donde se ejerce sino únicamente su forma, la que inscribe la verificación de la igualdad en la institución de un litigio, de una comunidad que sólo existe por la división (Rancière, 1996, p. 47).

El autor apela por el régimen estético de la modernidad a partir de la indagación de un nuevo reparto de lo sensible, en el que la demarcación no pasa por la posición de clase aristócrata y el conformismo político, sino que se traduce en el campo político en la inclusión de los otros, que puede ser cualquier agente o colectivo que a través de su voz logra ubicarse en los intersticios de la política y la estética como espacio de problematización, que construye la posibilidad de existir en una comunidad política libre (Martín Barbero, 2010, p. 17). 
La estética es primeramente la liberación con respecto a las normas de la representación, en segundo lugar la constitución de un tipo de comunidad de lo sensible que funciona de acuerdo con la modalidad de presunción, del como sí que incluye a quienes no están incluidos haciendo ver un modo de existencia de lo sensible sustraído a las partes de las partes y sus partes. (Rancière, 1996, p. 79)

Para Rancière, "la estética, es lo que pone en comunicación unos regímenes separados de expresión” (1996, p. 78). De ahí que el registro de la política, desde una perspectiva estética, permita reconocer ese ordenamiento que subyace a las comunidades políticas, y solo vinculando relaciones que aparentemente no tienen nada que ver con dicho orden es que se puede configurar una escena de litigio, que a partir de un espacio de ficción permita cuestionar el orden de las distribuciones. "La política estética fuerza la construcción de un sujeto que se des-identifica del papel de víctima y no propone ser parte del orden de experiencia existente, sino mostrar su arbitrariedad y poner en juego nuevas visibilidades, potenciando la construcción de otros modos de distribución y reparto" (Escudero, 2009, p. 33).

Sumado a lo anterior, Rancière sostiene "que la autonomización de la estética como nuevo nudo entre el orden del logos y la participación de lo sensible forma parte de la configuración moderna de la política" (1996, p. 79). Esto en contraste con la concepción clásica de la política que obedecía a una vía única de racionalidad, de visibilidad y de oportunidad de inclusión en el ámbito de lo público, que se concretaba únicamente en ámbitos avalados como tal y que respondía a unas virtudes que excluían a los que no hacen parte en las cuentas del démos.

La política moderna se libra en primer lugar en esta distinción de una comunidad sensible virtual o exigible por encima de la distribución de los órdenes y las funciones. La política antigua obedecía al solo concepto del demos y sus propiedades impropias, abriendo el espacio público como espacio de litigio. La política moderna obedece a la multiplicación de las operaciones de subjetivación que inventan mundos de comunidad que son mundos de disentimiento, a los dispositivos de demostración que son, en cada momento, al 
mismo tiempo argumentaciones y aperturas de mundo, la apertura de mundos comunes -lo que no quiere decir consensuales-, de mundos donde el sujeto que argumenta se cuenta como argumentador. Este sujeto es siempre un uno de más. [...] Es un sujeto excedente que se define en el conjunto de las operaciones que demuestran esa comprensión manifestando su estructura de diferencia, su estructura de relación entre lo común y lo no común. La política moderna existe por la multiplicación de los mundos comunes /litigiosos previos en la superficie de las actividades y los órdenes sociales. Existe por los sujetos que autorizan esta multiplicación, sujetos cuya cuenta siempre es supernumeraria. (Rancière, 1996, p. 79)

Desde esta mirada, la estética produce un sentido cambiante a la concepción del ejercicio de lo político, descentrándola de la relación Estadoindividuo como campo único de acción, y la ubica en la cotidianidad de los agentes, en la superposición de lo público y lo privado, ámbitos que configuran nuevas formas de enunciación y de significación como manifestación de lo político.

La experiencia estética, en oposición a la racionalidad del logos, amplía la posibilidad de creación y enunciación de otras narrativas o discursos, configurándose desde el ámbito de lo sensible y lo metafórico, lo que produce otros ámbitos de litigio y de disenso que permiten ampliar o traspasar los límites de la significación y darle sentido a partir de casos específicos.

La invención política se opera en actos que son a la vez argumentativos y poéticos, golpes de fuerza que abren y reabren tantas veces como sea necesario los mundos en los cuales esos actos de comunidad son actos de comunidad. Es por eso que en ella lo "poético" no se opone a lo argumentativo. Es por eso, también, que la creación de los mundos estéticos litigiosos no es la simple invención de lenguajes aptos para reformular problemas intratables en los lenguajes existentes. (Rancière, 1996, p. 81)

Así, desde el campo de la estética (más allá de los regímenes estéticos que han permitido entenderla), es decir, desde una concepción amplia 
que da apertura a infinidad de manifestaciones metafóricas de las múltiples realidades, es donde los agentes pueden configurar — como afirma Rancière (1996) — "momentos poéticos en los que los creadores forman nuevos lenguajes que permiten la redescripción de la experiencia común, inventan nuevas metáforas, llamadas más tarde a entrar en el dominio de las herramientas lingüísticas comunes y de la racionalidad consensual" (Rancièrep. 81).

Con lo anterior, la experiencia estética encarna hoy un lugar privilegiado de la condición humana como productora de subjetividades, sensibilidades, identificaciones y formas de vinculación que producen nuevos lenguajes, que les dan oportunidad al cuerpo y a otras formas de creación artística como el teatro, las creaciones audiovisuales o el juego a hacer visibles otras formas de ver, de pensar, de hacer, de contar y de construir lo común. "El arte no anda haciéndose por "su lado" sino inmerso en los muy diversos y contradictorios lados y movimientos que deshacen y rehacen hoy la sociedad entera" (Martín Barbero, 2010, abril, p. 2).

Pero el consenso exclusivo no se deshace únicamente en momentos de excepción y por obra de especialistas de la ironía. Se deshace todas las veces que se abren mundos de desacuerdo y disentimiento. Hay política si la comunidad de la capacidad argumentativa y la capacidad metafórica es susceptible de suceder en cualquier momento y por obra de quienquiera. (Rancière, 1996, p. 81)

\section{A modo de cierre}

Con este recorrido, se puede advertir que existen diversos discursos teóricos que encuentran puntos de relación o de distanciamiento frente a lo político. Por una parte, se evidencia cómo el pensamiento político, desde los griegos hasta Smith, posiciona la idea de cancelar la dimensión conflictiva de lo político, en el corazón mismo de la política, como forma de organización e institucionalidad acorde a una búsqueda de paz, convivencia o armonía que configura el ideal de una sociedad. Asimismo, se hace evidente de qué manera lo político se 
entiende como parte de la política, es decir, se legitiman las formas de poder que regulan la vida en sociedad a través de un marco jurídico y se cancela en él toda potencia individual de transformar lo social; de esta manera, se niega la distinción que reside en el sujeto como instituyente (Castoriadis, 1986), que permite concebir la sociedad y la política como sistemas abiertos que se configuran permanentemente.

Lo que se propone al profundizar en el concepto de lo político es justamente caracterizar la acción política de agentes como los jóvenes, que históricamente han sido excluidos de la política y quienes aparentemente no tienen ninguna influencia o alcance en la configuración de lo social. Al concebir lo social como un campo en movimiento, es decir, que se complejiza por lo político como un ámbito de aparición (Arendt, 1993), de enunciación (Rancière, 1996), de autonomía (Castoriadis, 2000), de desfijación de sentido y antagonismo (Laclau y Mouffe, 2004), se está aludiendo a una posibilidad de resignificar la política y lo social a manera de fruto de la acción política de agentes como los jóvenes, quienes a través de prácticas estéticas introducen sentidos y significaciones que están ampliando otras perspectivas de construir lo común; en últimas, de ampliar el ámbito de significación social a través de lo político.

Comprender cómo a través de la experiencia estética se configuran otros sentidos de la acción política en la contemporaneidad y en la realidad colombiana es un reto para las ciencias sociales, pues se introduce además un principio de contingencia y acontecimiento que determina las movilidades y transformaciones que en el ámbito de lo público y lo privado configura la condición ontológica de lo político. 
